\title{
Utilizing thermal building mass for storage in district heating systems: Combined building level simulations and system level optimization
}

Dominkovic, D. F.; Gianniou, P.; Münster, M.; Heller, A.; Rode, C.

Published in:

Energy

Link to article, DOI:

10.1016/j.energy.2018.04.093

Publication date:

2018

Document Version

Peer reviewed version

Link back to DTU Orbit

Citation (APA):

Dominkovic, D. F., Gianniou, P., Münster, M., Heller, A., \& Rode, C. (2018). Utilizing thermal building mass for storage in district heating systems: Combined building level simulations and system level optimization. Energy, 153, 949-966. https://doi.org/10.1016/j.energy.2018.04.093

\section{General rights}

Copyright and moral rights for the publications made accessible in the public portal are retained by the authors and/or other copyright owners and it is a condition of accessing publications that users recognise and abide by the legal requirements associated with these rights.

- Users may download and print one copy of any publication from the public portal for the purpose of private study or research.

- You may not further distribute the material or use it for any profit-making activity or commercial gain

- You may freely distribute the URL identifying the publication in the public portal 


\title{
Utilizing thermal building mass for storage in district heating systems:
} combined building level simulations and system level optimization

\author{
D. F. Dominković* \\ Department of Energy Conversion and Storage \\ Technical University of Denmark (DTU), Frederiksborgvej 399, Roskilde, Denmark \\ e-mail: dodo@dtu.dk \\ P. Gianniou \\ Department of Civil Engineering \\ Technical University of Denmark (DTU), Niels Koppels Allé, Kgs. Lyngby, Denmark \\ e-mail: pagian@byg.dtu.dk \\ M. Münster \\ Department of Management Engineering \\ Technical University of Denmark (DTU), Produktionstorvet, Kgs. Lyngby, Denmark \\ e-mail:maem@dtu.dk
}

\author{
A. Heller \\ Department of Civil Engineering
}

Technical University of Denmark (DTU), Brovej, Kgs. Lyngby, Denmark

e-mail: alfh@byg.dtu.dk

C. Rode

Department of Civil Engineering

Technical University of Denmark (DTU), Niels Koppels Allé, Kgs. Lyngby, Denmark

e-mail: car@byg.dtu.dk

\begin{abstract}
Higher shares of intermittent renewable energy in energy systems have raised the issue of the need for different energy storage solutions. The utilization of existing thermal building mass for storage is a costefficient solution. In order to investigate its potential, a detailed building simulation model was coupled with a linear optimization model of the energy system. Different building archetypes were modelled in detail, and their potential preheating and subsequent heat supply cut-off periods were assessed. Energy system optimization focused on the impact of thermal mass for storage on the energy supply of district heating. Results showed that longer preheating time increased the possible duration of cut-off events. System optimization showed that the thermal mass for storage was used as intra-day storage. Flexible load accounted for $5.5 \%$ to $7.7 \%$ of the total district heating demand. Furthermore, thermal mass for storage enabled more solar thermal heating energy to be effectively utilized in the system. One of the sensitivity analyses showed that the large-scale pit thermal energy storage and thermal mass for storage are
\end{abstract}


complimentary. The cut-off duration potential, which did not compromise thermal comfort, was longer in the newer, better insulated buildings, reaching 6 hours among different building archetypes.

Keywords: thermal energy storage in buildings; thermal mass; district heating; energy supply optimization; thermal autonomy; heat flexibility

\section{Introduction}

District heating systems produce heat centrally and distribute it to the end consumers via transmission and distribution pipes. Heat storage can be used when a mismatch between the timing of production and demand for heat occurs. Other solutions include peak boilers that can quickly be dispatched. When comparing heat storage and peak boilers, the former usually has large capital costs and low operating costs, while the latter usually have larger operational costs and lower capital costs.

All buildings, which are connected to district heating systems, have certain thermal capacities for storing heat inside the structure of the buildings. Contrary to the usual heating storage types such as hot water tanks or water pits, the capital costs for the utilization of thermal mass for storage is close to zero, as the building structure does not have to be modified additionally. Thus, utilizing thermal mass for storage could be an efficient solution for load shifting and/or peak shaving in district heating grids. The objective of this paper is to analyse the potential of utilizing thermal mass for storage in district heating systems in order to reduce the operational costs of the district heating systems by optimally shifting the district heat load. District heating systems are dominated by the peak demand during a few morning hours [1], which results in higher operational costs of the district heating systems.

One of the main findings from a recent review of the district heating and cooling systems has indicated that district energy systems are more efficient than individual heating and cooling systems, based on many projects reviewed across the world [2]. Thermal energy storage was one of the emphasized technologies that has a potential to further increase efficiency into current district energy systems [2]. It has been anticipated that district heating should play an important role in future renewable energy systems [3]. Moreover, authors have concluded that the future smart thermal grids will involve more energy efficient buildings, as well as integration with electricity and gas grids [3]. For the case of future energy system of Denmark, the share of $55-57 \%$ of district heating in the total heat demand could be cost-effective from the energy system point of view, although significant heat savings in the building sector have been anticipated [4]. Another recent international review of district heating and cooling systems claimed that those systems have strong potentials to be feasible supply options in a future world [5]. An author has reported that large national district heating research projects are being supported in Denmark, Germany, Sweden and China [5]. It was further concluded that heat recovery and heat based on renewable energy sources is larger in the European Union than in the rest of the world [5]. Nevertheless, the future energy system will need to balance out the potential energy savings in the building sector with the renewable energy supply in a costeffective way. One study showed that the energy demand of buildings could be cost effectively reduced by $12-17 \%$ by the year 2015 [6]. The same study has shown that larger savings are to be expected in individual heating areas than in district heating areas. 
Thermal energy storage has proven to be a technology that can be beneficial towards the energy efficiency of a building by contributing to an increased share of renewable energy and/or reduction in energy demand or peak loads for both heating and cooling [7]. Thermal building mass for storage could serve as a supplement to already existing storage solutions, such as hot water tanks. The reason for the latter is the low capital costs in thermal building mass storage type, as no physical alterations to the buildings are needed. Many different thermal storage options have been researched and some are already implemented on a large scale. Thermal storage can be realized in several different ways. They can be central (closer to the supply side of the system) or decentral (close to the consumer side of the system). Another division considers the thermodynamic nature of the way heat is stored, i.e. whether it is latent, sensible or thermochemical storage. Seasonal thermal energy storage has been reviewed in [8] and it was concluded that although it is a promising technology, its cost does not make it applicable to all projects, even less for single family houses. Furthermore, a review of promising candidates for chemical heat storage has been reviewed in [9], highlighting its significant potential due to the high thermal storage density, but also its low efficiency, special consideration of safety and large initial investment that is required. Thermal energy storages using phase change materials (PCMs) have been reviewed in [10]. One of the main aspects of PCMs is their low thermal conductivity (usually between 0.2 and $0.7 \mathrm{~W} / \mathrm{mK}$ ), thus requiring the use of complex heat exchanger geometries to obtain required heat transfer rates from latent heat storage containers. Regarding thermal storage building integrated systems, one study reviews it extensively [11]. The authors have concluded that active storage systems in the building envelope could be used when constructing new buildings. The integration of active thermal storage in buildings should be planned during a design phase in order to overcome the problems of availability of space for installations. In the same study, it has been claimed that both commercial and public buildings have huge potential on implementing thermal energy storage in double skin façade as well as in ventilation systems.

The utilization of short term heat storage in the sensible thermal mass of the buildings has been investigated in a number of studies during the last years. The zero investment cost that is required for the utilization of the thermal mass along with the capacity that is available in the majority of buildings in northern climates makes it a promising storage solution. One study of combined thermal energy storage and buildings has also dealt with a potential of using thermal mass of buildings for sensible heat storage [7]. It was concluded that the thermal energy storage can result in increased energy efficiency in buildings, reduced emissions, increased efficiency of HVAC equipment and reduced peak loads in the system [7]. It was further argued that it is important always to fulfil specific demands and conditions that differ from building to building [7]. In a Danish study [12], two residential buildings with different states of insulation and air tightness were examined in terms of heat storage and heat conservation. The findings showed that the potential of the thermal mass depends on many factors (level of insulation, heat emission system etc.) and varies significantly over the season. The poorly insulated building could offer short thermal autonomy or heat flexibility meaning the time where the building can perform without activating a heating system, while the energy efficient passive house had a much higher time constant. This means that large amounts of heat could be shifted for shorter periods of time in poorly insulated buildings. On the contrary, a complete switch-off of the heating system could be achieved in the passive house for more than $24 \mathrm{~h}$ without violating the thermal comfort of the occupants.

Demand side management (DSM) can be defined as a modified consumer energy demand through various methods. Usually, the balancing of intermittent generation and load shifting from peak demand hours to 
off-peak demand hours are the most important targets of the DSM. A study by [13] investigated the potential of structural thermal mass of a single family dwelling for demand-side management (DSM) equipped with an air-to-water heat pump coupled with low temperature heat emission system, as well as a photovoltaic system in South-eastern Europe. The findings showed that the structural storage capacity has strong potential for shifting peak electricity loads for heating to off-peak hours. The DSM potential was found to be higher for massive buildings than for light-weight buildings.

Furthermore, the interaction between the heating system and the available thermal mass is significant. The authors in [14] have addressed that even after very short overheating periods, the heating demand for the following hours can be reduced significantly (up to 20\%) utilizing the thermal storage capacity of the examined building, which included a hydraulic radiator-based heating system. The main limiting factors to the discharging rate were the slow temperature increase within the thermal mass and the heat conduction into the deeper wall layers. Moreover, the influence of the ambient temperature to the storage performance of the thermal mass has been highlighted. The authors conclude that good DSM can be achieved with shorter overheating periods at cold weather conditions. In addition, a Swedish pilot study [15] investigated the storage potential of the thermal inertia of five multi-family residential buildings connected with a district heating $(\mathrm{DH})$ system. Results showed that heavy-weight buildings, with a structural core of concrete, can tolerate large variations in heat deliveries while still maintaining an acceptable indoor climate. Thus, the control can be applied in many buildings in $\mathrm{DH}$ systems at a relatively low cost. The study also demonstrated that degree hours instead of a fixed time constant can be a more accurate metric to represent variations in indoor temperature caused by the utilization of the thermal mass of the buildings. Although many examples of the simulated uses of thermal mass for storage have been reviewed on a building scale, there is a lack of cases calculating the potential of thermal mass for storage on a system scale.

A few papers dealt with the analysis of the thermal mass for storage potential on a system scale. Authors in [16] have presented a framework for planning cost effective operation of HVAC systems utilizing multibuilding thermal mass. They have used a business-economic optimization approach and optimized thermal mass for storage of commercial buildings [16]. However, in their approach, thermal mass for storage was used to impact only the power sector while their time frame was one day. A simulation platform and different control strategies for utilizing the thermal mass for storage has been presented in [17]. The authors have concluded that single buildings only have marginal influence on the energy system flexibility and that extension of the models to the entire city is needed [17]. They have also assessed the potential of utilizing the thermal mass for storage to increase the flexibility of the power sector. A detailed dynamic and grey box model has been developed in [18]. They have shown that between $3 \%$ and $14 \%$ of the load can be shifted by utilizing the thermal mass for storage [18]. However, they have also considered the impact of flexibility solely on the power sector and not on the district heating sector [18]. Furthermore, the buildings they have modelled were well insulated and no behaviour of older buildings has been presented. The primary energy supply in the power sector was dominated by gas (40\%), followed by nuclear (35\%), waste and renewables (10\%) and hydro (9\%) [18].

To continue on the latter, one paper has proposed a resistance-capacitance representation of building thermodynamics in order to incorporate thermal mass for storage into an integrated planning model [19]. They have used it for an Irish case study and their focus was on partially decoupling of heat and electricity 
demand, without including district heating systems into the model [19]. The authors concluded that by utilizing building thermal inertia, electrified residential heat costs can be reduced to the cost of benchmark technology, which were gas boilers in the Irish case [19]. The energy supply in the power sector was dominated by wind (40\%), coal, peat, gas, oil and hydro. Other authors used Balmorel model with the thermal building model add-on in order to represent thermal mass for storage [20]. The model has not taken transient behaviour of heat transfer into account, while the average annual building energy consumption was taken from the literature without detailed modelling [20]. They have concluded that by utilizing thermal mass for storage, peak load could be shaved and that heat pumps operation could be prioritized for hours with low marginal generation costs [20].

So far, most of the research papers dealt with detailed calculations of thermal mass for storage on a building scale for specific building archetypes. The majority of the papers that modelled thermal inertia on a system scale have not captured dynamics of the heat transfer and transient behaviour well enough during the hours after the DSM event using reduced-order models. Moreover, almost no literature has been found, which focuses on the impact of utilizing thermal mass for storage on district heating supply in general; the presented papers have rather focused on the potential benefits that the thermal mass for storage could have on the power sector. Thus, the aim of this paper is to analyse building performance of different archetypes during the DSM events and to analyse the impact of DSM events on district heating systems. Moreover, the main objectives of the paper is to give an overview of the energy flexibility potential that an urban residential building stock can give to the energy grid and to project this potential into the future. In order to have a sufficiently detailed model, a two level modelling approach is proposed. First, detailed simulation of existing building archetypes shall be carried out in order to estimate their thermal autonomy or heat flexibility potential, obtain detailed heat demand pattern after the DSM events and possible additional peaks in heat demand of different building archetypes. Second, simulation output data shall be used as input for linear optimization model that optimizes the whole energy system and analyses the potential of thermal mass for storage on a system scale. In this way, the realistic building energy performance is captured in great detail while the analysis of the impact of DSM events on the energy system on a district scale brings clarity about the total potential of smart control in district heating systems.

The outline of the paper is structured as follows: the building simulation and system optimization models are described in the Methods section. The city of Sønderborg was chosen for the case study and specifics of its energy system and the representative buildings are described in the Case study section. The potential of the thermal mass for storage is presented in the Results section. The results are put into perspective and compared with the findings from the other studies in the Discussion. Finally, the main points are summarized in the Conclusions section.

\section{Methods}

The following section presents the methods that were applied to model the investigated building stock, calculate the indicators and conduct the energy system optimization analysis. First, a detailed building energy model is presented. Second, the system indicators for evaluation of thermal mass for storage are introduced and different building heating scenarios presented. Third, an energy system optimization model is described. The energy system optimization model used the output of building simulations in terms of 
thermal autonomy, a difference in energy consumption compared to the reference case and the distribution of preheating and after cut-off heating demand as an input for running the optimization. Different steps used in the model are presented in Figure 1.

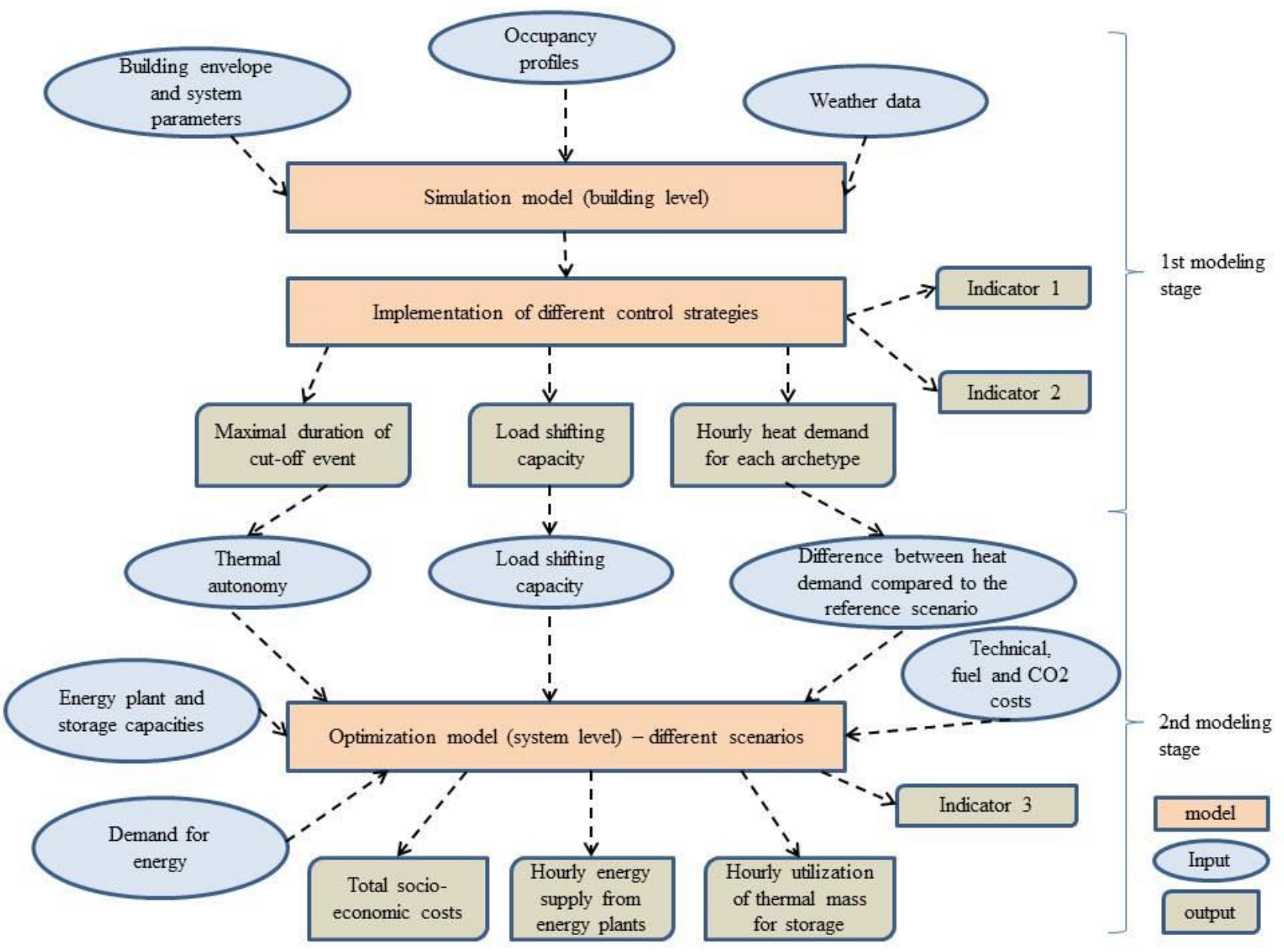

Figure 1. The flow diagram of the two-stage modelling process

2.1. Building energy modelling

The current analysis was conducted by use of building models. The building model and energy simulations were run in IDA ICE Version 4.7 [21]. The model behind the simulation tool is a detailed physical representation of the transient heat transfer phenomena taking place in a building. The model describing the external walls is a finite differences model of a multi-layer component. The buildings were simulated as single-zone models. The models were run with the Danish Design Reference Year (DRY) weather file [22]. These weather conditions are characterized by very cold winter temperatures. The monthly degree-days for the given climate and the annual outdoor temperature distribution according to [23] are presented in Appendix B. Based on literature, the utilization of thermal mass during times of very low ambient temperatures can have a good potential for DSM strategies. A cold and grey winter day was selected out of the DRY file to run the following experiment, during which the solar gains were very low and the average ambient temperature was $-3^{\circ} \mathrm{C}$. Thus, the heat losses were increased for the specific examined case. The 
global radiation for an exemplary week in January is presented in Appendix B. However, the ambient temperature on the selected day did not fall below $-12^{\circ} \mathrm{C}$, which is the dimensioning temperature for heating systems in Denmark. Deterministic occupancy profiles were modelled representing typical house living schedules, where there was no occupancy during $8 \mathrm{am}-3 \mathrm{pm}$ on weekdays. The heat supply system was $\mathrm{DH}$ and the heat emission system were hydronic radiators. No mechanical cooling or ventilation was assumed being installed in the buildings. The infiltration rate was determined based on wind-driven air flow. Internal walls and furniture mass were modelled taking into account the floor area that they covered, their material, thickness and the convective heat transfer coefficient.

The segmentation and characterization of the building stock was done according to [24]. Six building archetypes were created to represent different types of buildings according to their construction age and energy refurbishment level. These can be seen inTable 2. The properties of the building envelope and systems were created according to the TABULA [25], EPISCOPE project [26] and national building regulations. The building models were calibrated according to [27] based on measured hourly energy data acquired from 54 households in the city of Sønderborg.

\title{
2.2. Definition of thermal autonomy and adopted indicators
}

The thermal autonomy of the building was defined as an indicator of heat flexibility standing for the duration of the thermal comfort period [28], during which the operative temperature inside the building does not fall below $18^{\circ} \mathrm{C}(1)$. This threshold was selected according to the Danish standard [29] corresponding to the third acceptable thermal comfort category, to reflect the degradation of indoor comfort in a straight-forward way. The thermal autonomy $[\mathrm{h}]$ was calculated on the basis of a heat supply cut-off experiment in the building models and was defined as the first indicator in our study.

$$
\operatorname{Ind}_{1}=\min \left\{t \mid T(t)=18^{\circ} \mathrm{C}\right\}
$$

The second indicator was defined as the difference in space heating demand of the building caused by the heating strategy implemented as opposed to the 'reference' heating demand ( 2 ). It was calculated on the basis of the thermal autonomy potential of each house. Indicator 2 [\%] was calculated on the 24-hour time period, starting from the hour 432 in the modelled year.

$$
\operatorname{Ind}_{2}=\frac{Q-Q_{\text {ref }}}{Q_{r e f}}
$$

\begin{abstract}
The exact time period was chosen as in none of the cases, the DSM event resulted in heat demand differences of more than $2 \%$ after the 24 -hour period.
\end{abstract}

\subsection{Overview of different strategies of DSM events}

To be able to determine the potential for thermal autonomy for all houses, heating control strategies were implemented. First, three different scenarios were created, which can be seen in Table 1. The first scenario included a complete cut-off of the heating system with no preheating or overheating strategy for a period 
that equals the thermal autonomy of each house, according to equation ( 1 ), so that operative temperature would not decrease below $18^{\circ} \mathrm{C}$. In order to make our results more robust, this strategy was implemented on the afore-mentioned cold weather conditions, so that an unfavourable case is represented. The heating set point of the reference operation of the heating system was set to $21^{\circ} \mathrm{C}$ in all scenarios based on the findings from calibrating the building models.

Then, the effect of preheating on the utilization of the thermal mass was investigated. The second scenario considered 2 hours of preheating the houses up to $24^{\circ} \mathrm{C}$, followed by a complete cut-off of the heat supply on the same cold day as the first scenario, during the same time. The duration of the cut-off was found such that it equalled the result of indicator 1 after the preheating was applied, so that the temperature would not decrease below $18^{\circ} \mathrm{C}$. According to the third scenario, 4 hours of preheating strategy up to $24^{\circ} \mathrm{C}$ was applied, followed by a heating cut-off on the same day, as previously explained. The duration of the heat cut-off was again adjusted so that it matched the new autonomy potential after the 4 hours of preheating. The three different strategies were implemented in the IDA ICE models through the option of variable controller heating set points ranging from $21^{\circ} \mathrm{C}$ in the reference case to $24^{\circ} \mathrm{C}$ in the preheating phase and to $18^{\circ} \mathrm{C}$ during the heat cut-off phase, which were continuous throughout the entire simulation year.

Table 1. DSM scenarios implemented to the models

\begin{tabular}{|c|c|c|c|}
\hline Scenario & Action & Preheating [h] & Notation \\
\hline 1 & Heat cut-off & 0 & CO \\
\hline 2 & Heat cut-off & 2 & CO_2hPH \\
\hline 3 & Heat cut-off & 4 & CO_4hPH \\
\hline
\end{tabular}

\subsection{Energy system optimization}

A linear continuous optimization model was used in order to represent an energy system. The optimization was run using Matlab interface and Gurobi solver, one of the solvers with the fastest computation times for solving linear optimization problems [30]. After the building simulations had been run, inputs from the building simulations such as autonomy time, the maximum capacity of avoided energy consumption during a cut-off event for each archetype, increased demand before and after the cut-off event and their corresponding distributions were incorporated in the optimization model. The simulated day from the first modelling stage was used as a pattern for all the cut-off events during the heating season $\left(1^{\text {st }}\right.$ October to $30^{\text {th }}$ April). A sensitivity analysis for the latter assumption was carried out and commented on in the Discussion section. Between $1^{\text {st }}$ May and $30^{\text {th }}$ September load shifting utilization was not allowed in the model as the space heating demand during that period was low. The optimization model includes the power, heat, gas and transport sectors. The optimization model used was developed, presented and validated in [31]. As a short overview, the model optimizes the energy system with an objective function set to minimize the total socio-economic costs of the energy system ( 3 ). It optimizes the whole energy system during one year on hourly resolution. 


$$
\begin{aligned}
& \min Z=\sum_{i=1}^{n}\left(f i x_{-} O \& M_{i}+\operatorname{lev}_{\text {inv }}\right) x_{i}+\sum_{j=1}^{m}\left({\text { var_o } O \& M_{j}}+\frac{f u e l_{j}}{\eta_{j}}+C O 2_{j} \cdot C O 2_{\text {inten }_{j}}\right) x_{j} \\
& +\sum_{k=1}^{p}\left(e l_{-} i m p \_\exp _{k}+g a s_{-} i m p \_\exp _{k}+\operatorname{dies}_{-} i m p_{k}+\text { petr_imp } p_{k}\right) x_{k}
\end{aligned}
$$

Energy plants were modelled using a black-box approach. The total socio-economic costs of the system incorporated levelized investment costs over the lifetime of the energy plants, fixed and variable operating and maintenance costs, fuel costs and costs of $\mathrm{CO}_{2}$ emissions. Other taxes were not included. A discussion about the reasons for including the cost of $\mathrm{CO}_{2}$ emissions and excluding the cost of other taxes in the total socio-economic costs can be found in [32]. The main reasoning for the latter is that the $\mathrm{CO}_{2}$ emissions cost represents the internalized negative externality in terms of climate change costs imposed to the society. A detailed explanation of all the terms used in $(3)$, as well as corresponding units, can be found in the Nomenclature, located at the end of this paper. As the goal of the optimization is to minimize the total socio-economic costs, different storage solutions will only be utilized if the corresponding load shifting can bring savings in the overall energy system costs. Based on the decision of the modeller, the model can optimize investments, too.

Furthermore, the model included all the district heating energy plants supplying the district heating network of the city, electricity plants (wind and PVs) erected as a part of the energy transition plan of the city and transportation demand for fuels. Electricity could be exported/imported over the system boundary (constrained by the transmission capacity), as well as fossil fuels for meeting the transport demand. Large (sensible) heat storage is another flexibility option that existed within the system boundary. Finally, gas CHP plant did not have a constraint on the minimum load level, which made it available to behave as a flexible generation technology. The building thermal mass for storage, which is the focus of this paper, was the last source of flexibility in the local energy system.

Congestion of the district heating grid and electricity grids was not modelled. Moreover, the model does not include dynamic modelling of the district heating grid due to the complexity of the size of the current model.

For this paper, the model was significantly expanded in order to include the potential of thermal mass for storage of different building archetypes. For each modelled building archetype, a set of variables for cut-off event, increased after cut-off heating demand and increased preheating were introduced. In order to meet the increased heat demand after the cut-off event, as well as before the cut-off event when the heating strategy included preheating, inequality constraints ( 4 ) and ( 5 ) were introduced.

$$
\begin{gathered}
{\text { cutof } f_{t, x} \cdot C_{x, y} \leq \text { preheating }_{t, x, y}} \\
\forall t \epsilon\{1, \ldots, 8760\}, \forall x \in\{1, \ldots, X\}, \forall y \in\{1, \ldots, Y\}
\end{gathered}
$$

Where cutof $f_{t, x}$ represents the avoided heat demand due to the cut-off event [MWh] for each building archetype $x$ in every hour $t$ of the year. $C_{x, y}$ represents coefficients of hourly difference in district heat 
demand in each preheating hour $y$ (compared to the reference heating demand pattern), obtained as a part of calculation for indicator 2 of the first step of the model. Finally, preheating $t_{t, x, y}$ represents the increased heat demand [MWh] prior to the anticipated DSM event.

$$
\begin{gathered}
\text { cutoff }_{t, x} \cdot C_{x, z} \leq \text { afterheating }_{t, x, z} \\
\forall t \in\{1, \ldots, 8760\}, \forall x \in\{1, \ldots, X\}, \forall z \in\{1, \ldots, Z\}
\end{gathered}
$$

Where afterheating $g_{t, x, z}$ represents increased heat demand after the cut-off event [MWh] in each after cut-off heating demand hour $z$.

The $C_{x, z}$ and $C_{x, y}$ coefficients were used to realistically capture the dynamics of the heating demand in hours before and after the cut-off events took place.

The sum of preheating hours $y$, the duration of cut-off event (equal to the value of Indicator 1 ) and after cut-off heating demand hours $z$ were set to 24 hours in order to match the indicator 2 from the first part of the model ( 6 ).

$$
y+\operatorname{Ind}_{1}+z=24
$$

In order to further integrate the first and the second part of the model, only one maximum capacity cut-off event was allowed in any 24-hour period ( 7 ). The latter constraint was introduced in order to acknowledge the calculation method used for the estimation of indicator 2 . However, the system could choose to have more than one cut-off event during any 24-hour period, as long as the sum of the avoided heat demands during all the cut-off events did not exceed the maximum capacity of a single cut-off event.

$$
\text { cutoff } f_{t, x}+\operatorname{cutoff}_{(t+1), x}+\cdots+\operatorname{cutoff}_{(t+23), x} \leq \operatorname{cutof} f_{\max , x}
$$

Where cutof $_{\text {max } x}$ represents maximum avoided heat demand during the cut-off event for each building archetype $x$, calculated in the first part of the model. Inequality constraint ( 7 ) allows more than one cutoff event during the 24-hour period as long as the sum of them does not exceed maximum possible cut-off demand.

Finally, after the optimization part of the model had been run, the economic indicator (Indicator 3) was calculated ( 8 ).

$$
\text { Ind }_{3}=\frac{C_{\text {operational,ref }}-C_{\text {operational }}}{C_{\text {operational,ref }}}
$$


Indicator 3 represents the difference in the operational costs of the district heating system, without the costs of the other parts of the energy system. Operational costs of the district heating system did not include investment costs of the energy plants. They were calculated using the equation ( 3 ) for the plants operating in the district heating network, without including the first and the third summation terms. The economic indicator encompassed operational costs of the district heating system only, as the district heating sector was the focus of research carried out in this paper. For the purpose of calculating the operational costs of DH systems, the income from cogeneration units selling electricity to the grid was included as revenue in the operational costs of the district heating systems, reducing the overall operational costs of the district heating system, while in the same time all the fuel costs of running the cogeneration units were included as expenditure.

\section{Case study}

The city of Sønderborg was chosen as the current case study. It is located in the south of Denmark with a population of 27,500 inhabitants as reported in 2011. It includes several types of energy supply plants and the whole municipality has started a transition towards net zero carbon until 2029. The highest share of heating demand is attributed to residential demand, accounting for $69 \%$ of the total heating demand (Figure 2). In Denmark, housing accounts for $64 \%$ of the total heat demand. As Sønderborg can be considered representative in terms of heat demand, and ambitious in terms of integrating variable renewable energy sources, it was decided to focus on the residential building stock of Sønderborg to investigate the potential for energy flexibility provided by the thermal mass included in the building envelope and internal walls. Around $53 \%$ of the area's heat demand is covered by the local district heating network [33].

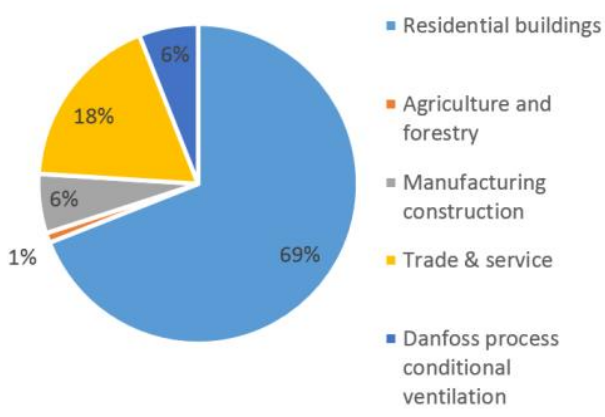

Figure 2. Allocation of heat demand on the building categories in Sønderborg 2007 [29]

\subsection{Characterization of Sønderborg' building stock}

The focus of the current study is on single-family houses (SFH), which represent the largest share of residential buildings in this area. The building stock of $\$ \varnothing$ nderborg was represented by archetypes as aforementioned. The categorization follows the general guidelines of the TABULA database. According to the TABULA project, in general there are ten typical Danish building archetypes corresponding to SFH [25]. One archetype belongs to each of the ten proposed age bands, which reflect a shift in building tradition and the introduction of building energy codes. The same age bands were used in our case to extrapolate the results 

of simulated building archetypes to the system level. Based on the available energy data that we had and used to calibrate the building models, six building archetypes were created representing the majority of the SFH in Sønderborg. The models of the archetypes are presented in Table 2. The construction age of all the building models, their gross floor areas along with the average heat loss coefficient (U-value) of the total building envelope and internal heat capacities are presented. The time constant of the buildings is also presented in Table 2. It is calculated as the ratio of the total heat capacity of the building and the total heat loss coefficient including transmission, ventilation and infiltration losses. The time constant gives an indication of the response pace of the building to different stimulations such as change in heating or outdoor temperature, hence being very relevant to the current study. It is evident that newer buildings have longer time constants. The total energy use intensity and peak energy demand over a full simulated year, which are also presented in Table 2, give an indication of the energy efficiency of the investigated building stock. The energy demand results were calculated after the models were calibrated according to the measured energy data and with the system properties and internal conditions that were described for the reference case. There are two archetypes corresponding to SFH built in the 1960's, since one of the two (1960's ref.) had undergone more extensive energy refurbishments based on the calibration findings. The U-values give an indication of the insulation state of the building envelope relating to how airtight each building is. The lower the U-value, the more airtight the building is and fewer thermal bridges it has. The refurbishment implemented in each building model/archetype -also affecting the heat loss coefficient of the building envelope- was decided based on the results of the calibration with measured energy data as mentioned earlier. The majority of the houses were made of heavy-weight insulated brick walls with an average thickness of $340 \mathrm{~mm}$. The internal walls in the majority of the investigated houses consisted of aerated concrete of $75 \mathrm{~mm}$ thickness and were designed based on typical floor plans of Danish SFH. The idea of using archetypes to characterize the building stock is that one archetype represents a building category having uniform characteristics in terms of building construction and systems that are regulated by building codes. Thus, the energy performance of buildings belonging in the same category will be quite similar making one archetype representing each category sufficient. More information about this approach can be found in [24]. The six building archetypes that were created represented $60 \%$ of the residential building stock and $55 \%$ of the district heating demand in Sønderborg. Most of the building stock not represented in Table 2 ( $26.4 \%$ of the building stock and $36.9 \%$ of district heating demand), were buildings built before 1930. The latter building stock has similar characteristics to the first archetype in terms of energy use intensity, dominated by low time constants. 


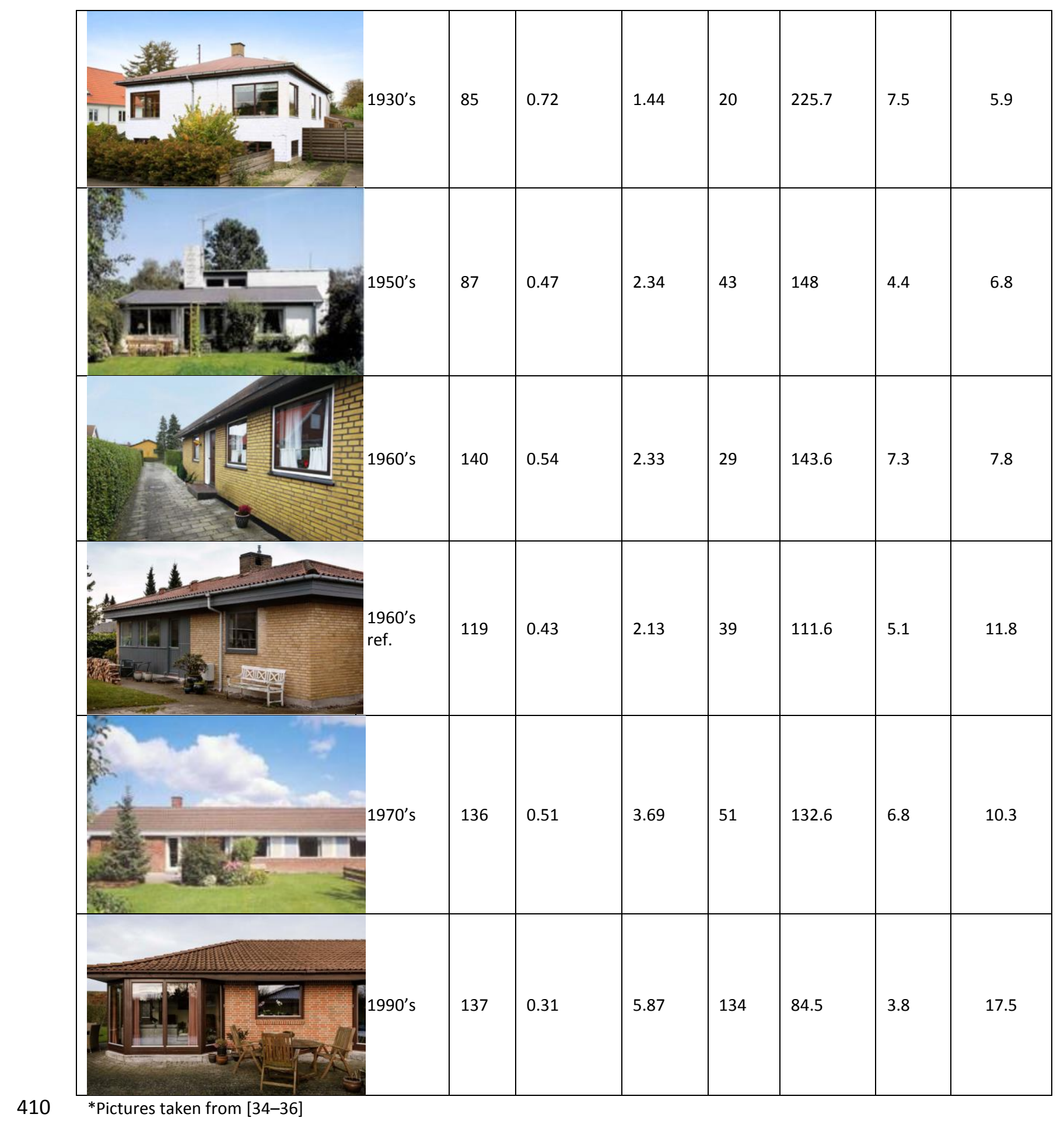




\subsection{Overview of Sønderborg district heating system}

In 2015 , the total district heat supplied to the customers in the city was $288.95 \mathrm{GWh}$ (not including $23 \%$ of distribution losses), based on information provided by the Sønderborg Fjernvarme, which is the operator of the district heating system. The Sønderborg DH operation data, such as volume flows, supply and return temperatures, as well as the circulation pumps electricity demand, can be found in great detail in Appendix B. According to the energy transition plan towards 2029, an increased share of households connected to the district heating systems has been anticipated [33]. The current district heating plants that supply the city of $\$ \varnothing$ nderborg with heat are listed in Table 3.

Table 3. The current district heat supply plants [31]

\begin{tabular}{|l|c|c|}
\hline Energy plant type & Electrical power $\left[\mathrm{MW}_{\mathrm{e}}\right]$ & Heat generation capacity $\left[\mathrm{MW}_{\text {th }}\right]$ \\
\hline Waste CHP & 4.5 & 20 \\
\hline Gas CHP & 40 & 53 \\
\hline Gas boilers & & 100 \\
\hline Solar heating (centralized) & & 5.2 \\
\hline Bio-oil & & 5.4 \\
\hline $\begin{array}{l}\text { Geothermal + biomass driven } \\
\text { absorption heat pump }\end{array}$ & & 12.5 \\
\hline
\end{tabular}

All household owners in Denmark are obliged to report certain information about their real estate, including the year of construction and last refurbishment of the building, energy consumption, heat energy source, type of the heating system, etc. in the so called BBR Database [37]. For the purpose of this paper, we have obtained the BBR data for the city of $\$ \varnothing$ nderborg through the ProjectZero company, the managing company of the net zero carbon energy transition of Sønderborg. Data has been cleansed removing unreasonable values. The high uncertainty in some of these variables used as inputs to the building models has been balanced by the calibration process as earlier mentioned, according to which measured energy data were used to calibrate the inputs of the building models so that the predicted and actual energy demand match.

The energy system of Sønderborg should undergo significant changes until the year 2029 and different renewable energy plants are anticipated [33,38]. The whole municipality of Sønderborg will try to achieve carbon neutrality by 2029. Important contribution towards this goal should be made by the district heating sector. Thus, in order to assess the effects of the potential utilization of the thermal mass for storage in the future energy system, an additional scenario (the $4^{\text {th }}$ one, designated $\mathrm{CO} \_2 \mathrm{hPH}$ _2029) was modelled. An overview of the plants, which should be installed until the year 2029 can be seen in Table 4. Only zerocarbon energy technologies are anticipated for the year 2029. Furthermore, it was complicated to extract the capacity of solar thermal anticipated in the DH network of the City of Sønderborg, as the transition plans are made for the whole municipality of Sønderborg. In order to cope with the latter, it was assumed that the maximum solar thermal generation would correspond to the $15 \%$ of the yearly DH demand in 2029. Effective solar thermal generation supplied to the district heating could be lower if there would not be enough demand during the peak generation hours and there would be a lack of heat storage capacity in the system. 
Table 4. Energy plants capacities anticipated in 2029

\begin{tabular}{lll}
\hline & Installed capacity $2015\left(\mathrm{MW}_{\mathrm{th}}\right)$ & Installed capacity $2029\left(\mathrm{MW}_{\mathrm{th}}\right)$ \\
\hline Gas boilers & 100 & 0 \\
Gas CHP & 53 & 0 \\
Waste CHP & 20 & 20 \\
Geothermal + biomass driven & 12.5 & 12.5 \\
absorption heat pump & & $*$ \\
Biomass boilers (including bio-oil) & 5.4 & 12 (heating capacity) \\
Large scale heat pumps & 0 & 40 \\
Solar heating & 5.2 & $4,000 \mathrm{MWh}$ \\
Heat storage & $4,000 \mathrm{MWh}$ & 180 \\
Wind turbines & 14.6 & 60 \\
Photovoltaics & 14.8 &
\end{tabular}

*Optimized by the model (a minimum capacity needed to satisfy the heating demand in all hours throughout the year)

It should be noted from Table 4 that the capacity of biomass boilers in the year 2029 was not fixed before the optimization was run. Opposite to the current portfolio of the DH supply plants, the future investments in the plants can be projected taking into account different technologies or flexibility options, such as utilizing the thermal mass for storage. In order to account for the potential savings of the capital costs, by reducing the installed capacity in the $\mathrm{DH}$ system, biomass boilers as a peak technology was also optimized in the CO_2hPH_2029 scenario. Thus, the resulting capacity of biomass boilers was the minimum capacity still being able to satisfy the $\mathrm{DH}$ demand in all hours during the year.

Furthermore, it is expected that the increased share of households will connect to the district heating grid. The $\mathrm{DH}$ demand should increase by $13 \%$ compared to the 2015 share, taking into account significant energy savings, which are anticipated in the building sector [33]. Furthermore, energy retrofit of buildings will increase the share of the buildings with longer thermal autonomy, i.e. more buildings will have better airsealed and thermally insulated envelope. Historically, the energy retrofit rate of the buildings in Denmark has been $1 \%$ per year $[39,40]$. We adopted the same rate until the year 2029 . Moreover, we assumed that the retrofitted buildings behave in the same way as the 1990's archetype, as those were the newest modelled buildings. Finally, for the 2029 scenario, the second strategy (with two hours of the preheating time) was used. The latter also means that the indicators 1 and 2 are equal in CO_2hPH and CO_2hPH_2029 scenarios. $\mathrm{CO}_{2}$ emission costs, as well as the average electricity prices can be seen in Table 5.

Table 5. Average wholesale electricity prices (based on Nordpool el-spot [41]) and CO2 emission prices used in the scenarios

\begin{tabular}{|c|c|c|}
\hline & 2015 & $2029 *$ \\
\hline Average electricity price $(€ / \mathrm{MWh})$ & $22.89[41]$ & 59.64 and [42] \\
\hline CO2 emission price $(€ / \mathrm{t})$ & $7.6[42]$ & $13.6[42]$ \\
\hline
\end{tabular}

*Real future prices, i.e. the future prices were adjusted for inflation (2016 prices)

One should also note that the assumed volatility of the prices was greater in the year 2029, as more intermittent renewable energy sources was assumed to be installed in the power grid. The spread between the highest and the lowest electricity price was 192.3 EUR/MWh in 2015, while the assumed spread was $302.6 € / M W h$ in 2029. 


\subsection{Results of the building energy modelling}

As mentioned in the Methodology, one representative winter day had to be identified and selected as the date when the experiments in the simulation part of the model would be carried out. These results were then reproduced according to the optimization results within the heating season of a year in the second stage of the model, making the system level results of the optimization part of the model robust. So, the heat cut-off was applied on January 19, which was found to be one average cold day of the reference year with the mean daily ambient temperature being $-3^{\circ} \mathrm{C}$ and very low solar gains in order to isolate their effect on heat flexibility.

The effect of the preheating strategies on the energy use for heating can be seen in Table 6. These results should be interpreted with regard to the information presented inTable 2 . The buildings with the lowest average U-values have the highest thermal autonomy potential $\left(\operatorname{lnd}_{1}\right)$, indicating that the effect of heat losses in the examined buildings is dominating. It should be also noted that even though the 1970's archetype has a longer time constant than the 1960's refurbished archetype, its better insulated envelope (thus lower U-value) results in a longer thermal autonomy potential. This validates the previous finding that heat losses have a more significant effect than the heat capacity of the building or its thermal mass for the specific investigated buildings under the cold and grey weather conditions. It should be noted that the internal wall mass for all archetypes was modelled in a very similar way, having similar construction characteristics (materials and wall thickness), as well as the share of the volume of internal walls to the floor area was assumed to be almost the same for all the different models. It is also evident that as the duration of preheating increases, the results of thermal autonomy (Ind1) increase in most archetypes. The effect of preheating is not pronounced on the newest archetype, which represents SFH built in the 1990's. This is attributed mainly to the fact that the building has airtight envelope leading to low heat losses, so its thermal autonomy potential is already high ( 6 hours) and is slightly improved by preheating, which is not evident due to rounding. According to [28], the effect of transmission losses exceeds the effect of thermal mass when it comes to thermal autonomy potential of a building and the peak load that is created after overheating strategies. Since the weather conditions on the day of the experiment were cold, the effect of the transmission losses on the specific indicators is outlined. Therefore, it is confirmed that buildings with airtight building envelopes and very low overall heat transfer coefficients would perform better in general with regards to heating demand. Looking at indicator 2, we observe that the cut-off of heating led to savings in space heating demand in all archetypes compared to the reference case when heating was always on, as expected. The heat losses were decreased due to the lower average internal temperature during the day of the cut-off. The highest decrease was observed for the newest archetype, which allowed the longest duration of cut-off. Indicator 2 could be positive or negative for the two preheating scenarios, as the duration of the preheating and of the subsequent cut-off may or may not lead to savings of space heating energy use. In the majority of the houses, even in the case of four hours of preheating up to $24^{\circ} \mathrm{C}$, the heating demand was still lower than the reference case except for the 1930's archetype and the 1970's archetype. Thus, it can be concluded that longer preheating times do not have the same effect in all buildings. 
Table 6. Results of indicator 1 (thermal autonomy) and 2 (difference in heating demand) 2

\begin{tabular}{|c|c|c|c|c|c|c|}
\hline & \multicolumn{2}{|c|}{ SCENARIO 1 (CO) } & \multicolumn{2}{c|}{ SCENARIO 2 (CO_2hPH) } & \multicolumn{2}{c|}{$\begin{array}{c}\text { SCENARIO 3 } \\
\text { (CO_4hPH) }\end{array}$} \\
\hline Archetype & Ind $_{1}[\mathrm{~h}]$ & Ind $_{2}[\%]$ & Ind $_{1}[\mathrm{~h}]$ & Ind $_{2}[\%]$ & Ind $_{1}[\mathrm{~h}]$ & Ind $_{2}[\%]$ \\
\hline 1930's & 1 & $-0.3 \%$ & 1 & $1.3 \%$ & 2 & $4.2 \%$ \\
\hline 1950's & 2 & $-1.9 \%$ & 3 & $-1.5 \%$ & 4 & $-0.7 \%$ \\
\hline 1960's & 1 & $-1 \%$ & 2 & $-2.1 \%$ & 2 & $-1.4 \%$ \\
\hline 1960's ref. & 2 & $-1.5 \%$ & 3 & $-2.0 \%$ & 4 & $-1.5 \%$ \\
\hline 1970's & 1 & $-0.3 \%$ & 2 & $-1.2 \%$ & 2 & $0.4 \%$ \\
\hline 1990's & 5 & $-14.6 \%$ & 6 & $-18.1 \%$ & 6 & $-15.2 \%$ \\
\hline
\end{tabular}

512 Operative temperatures and heat consumption of the 1990's archetype and the 1960's archetype during the 24-hour period around the simulated cut-off event can be seen in Figure 3 and Figure 4, respectively. The latter represents the archetype with short time constant and a low thermal autonomy ( 1 to 2 hours in different scenarios), while the former presents the archetype with the longest time constant and longer thermal autonomy (5 to 6 hours). For the implemented DSM strategies, we can see that operative temperature inside the $1990^{\prime} \mathrm{s}$ and $1960^{\prime} \mathrm{s}$ archetypes varies between $18^{\circ} \mathrm{C}$ and $22^{\circ} \mathrm{C}$. Furthermore, the preheating scenarios $\mathrm{CO}_{-} 2 \mathrm{hPH}$ and $\mathrm{CO}_{-} 4 \mathrm{hPH}$ lead to higher initial internal temperatures for both archetypes. The thermal comfort remains to be acceptable in all cases according to [29]. When comparing the reference case and the cases with the occurring DSM events, one can note new peaks in heat demand. These peaks occur both during preheating and after heat cut-off phase. We can observe that the effect of preheating strategies is minimized on the archetype of 1990's leading to similar thermal autonomy results. The magnitude of the peak load that is created after the cut-off is similar for all three scenarios and it is defined by the capacity of the heating system. For the same archetype, even though the preheating set point is set to $24^{\circ} \mathrm{C}$, this cannot be achieved within the given time, with the maximum operative temperature inside the house being $21.8^{\circ} \mathrm{C}$ for the $\mathrm{CO} \_4 \mathrm{hPH}$ scenario. Despite the 4-hour preheating, the thermal autonomy is not much prolonged as mentioned earlier due to the long-time constant and the low heat loss coefficient of the building envelope of the 1990's archetype. We can see that the operative temperature stabilizes in the three scenarios at the end of the day reaching almost the same value of the reference case where no cut-off was applied. Looking at the heat power graph of Figure 3, it can be observed that the peak load that is created after the heat cut-off is almost equal for the three scenarios, independent of the preheating strategy as already mentioned. Similarly, 1960's archetype has a slightly increased thermal autonomy after preheating scenarios $\mathrm{CO}_{-} 2 \mathrm{hPH}$ and $\mathrm{CO}_{-} 4 \mathrm{hPH}$ as seen in Figure 4 . The magnitude of the peak load seems again to be independent of the preheating strategy and is very much defined by the maximum capacity of the heating system that is almost fully utilized in these cases of a sudden internal temperature drop. It should be noted that the heating system is dimensioned in the construction phase of the building. So, when the building undergoes energy refurbishments, the heat demand may be reduced but the capacity of the heating system remains the same as before. That is the reason that the older archetype has higher peak loads after the cut-off compared to the newer archetype. 
541 the setup of the controller that was set to take average values of very short time steps to eliminate 542 temperature changes within a few minutes.

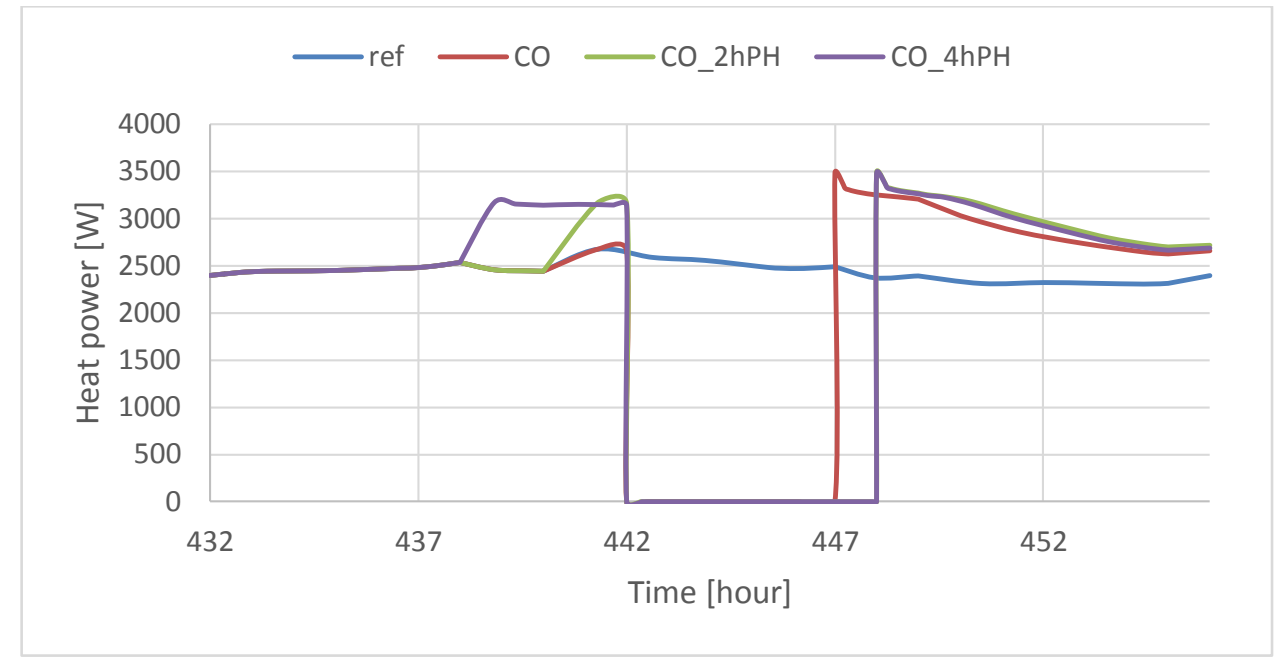



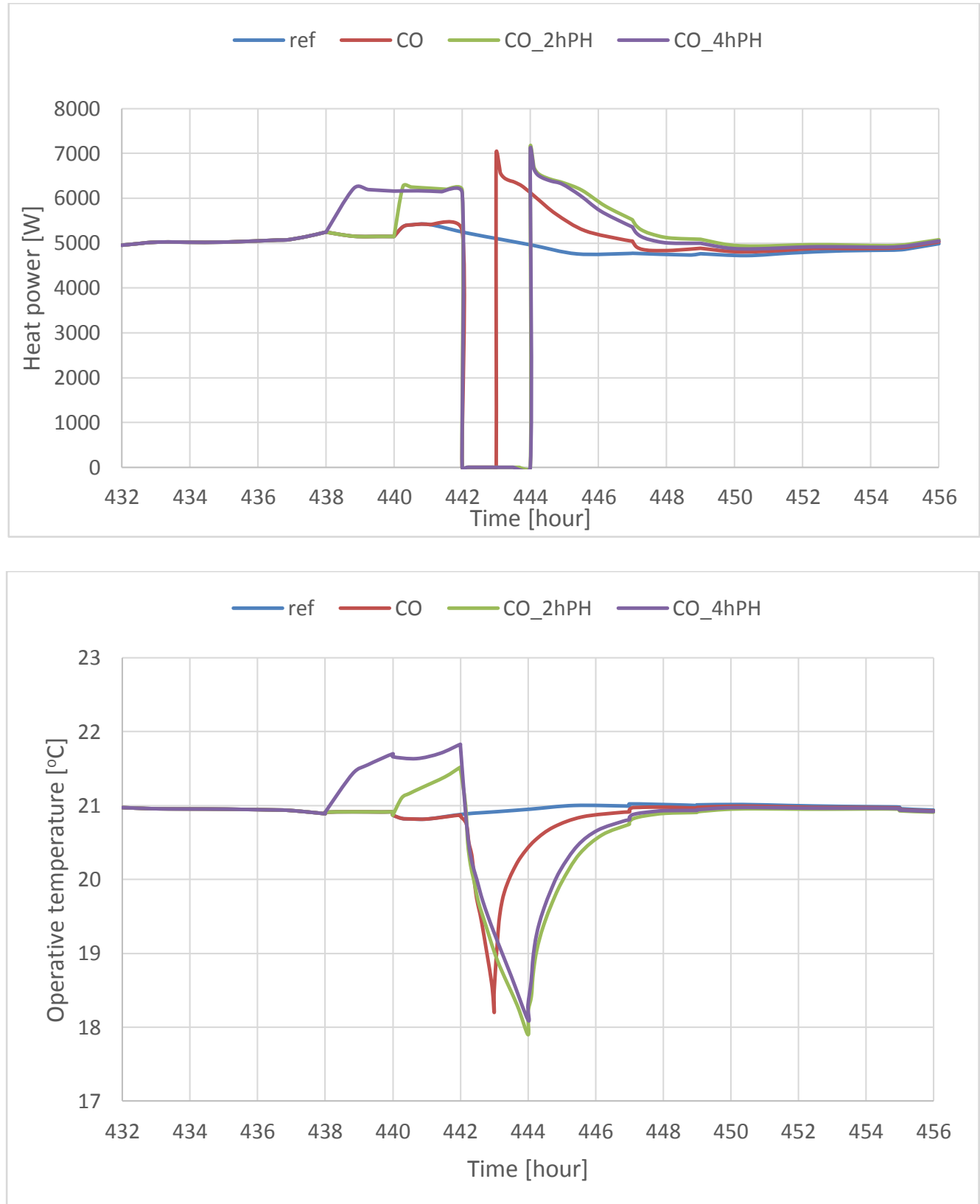

\subsection{Results of the energy system optimization}

The total shifted heat demand during the year, in terms of avoided heat demand during the cut-off events, for the 3 different strategies for the year 2015 and strategy two for the year 2029 (scenario CO_2hPH_2029) can be seen in Figure 5. 


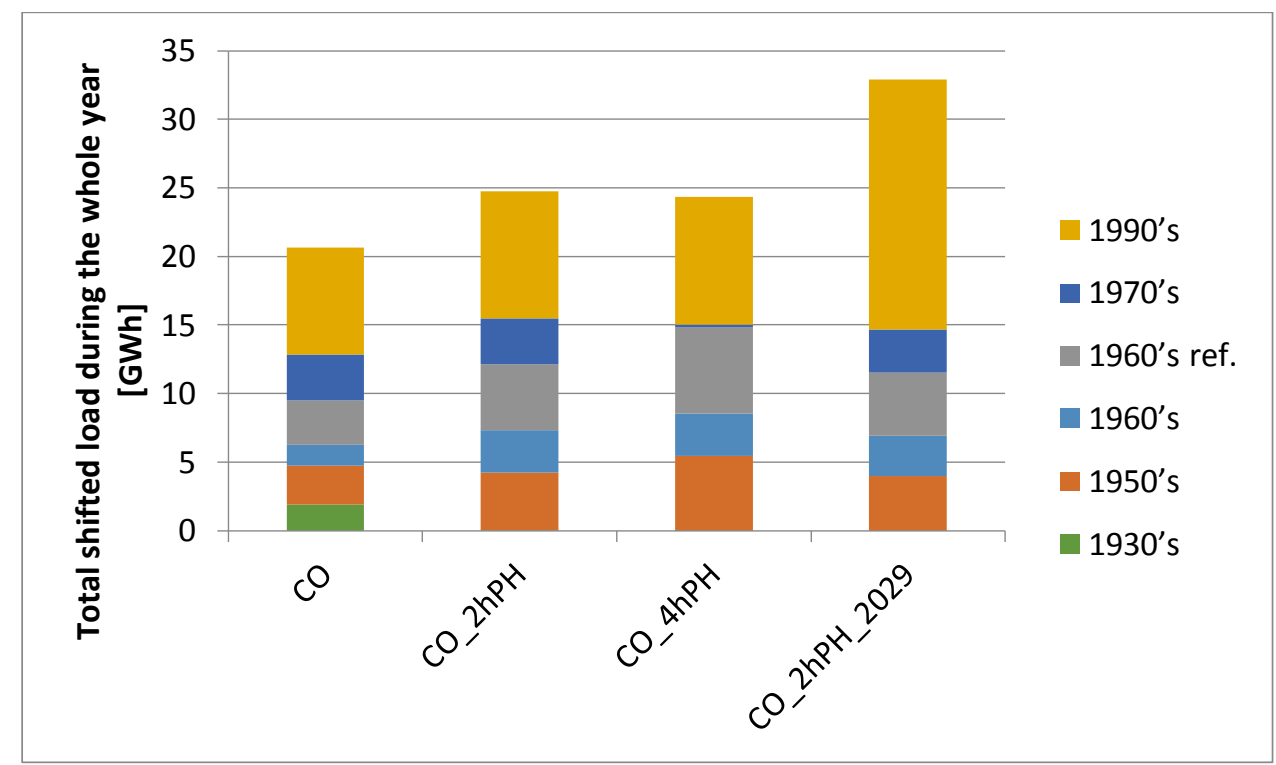

Figure 5. The total amount of shifted heat demand on the system scale in different scenarios for one whole heating season

In all the scenarios, the newer archetypes contributed more to the overall load shifting than the older ones. The oldest houses, represented by the 1930's archetype were utilized only in the CO scenario. All other archetypes contributed to the load shifting in all the scenarios. Archetypes 1960's ref, 1970's and 1980's accounted for $65 \%-70 \%$ of the total shifted load, in the first three scenarios. Moreover, the relatively old building archetype 1950's was often utilized, especially in scenarios CO_2hPH and CO_4hPH when it had larger autonomy ( 3 and 4 hours compared to the 2 hours in the CO scenario). It was found feasible to utilise almost all of the identified load shifting potential. The maximum possible capacity of the load shifting was $5.6 \%$ to $8.4 \%$ of the total DH demand of the city of Sønderborg in different scenarios. The real activation of the thermal mass for storage in different scenarios showed that the shifted load accounted for $5.5 \%$ to $7.7 \%$ of the total $\mathrm{DH}$ demand in the different scenarios.

Differences in operational costs of the district heating system, represented by Indicator 3 , can be seen in Table 7.

Table 7. Comparison of the operational costs of district heating in the city of Sønderborg in different scenarios (indicator 3).

\begin{tabular}{|c|c|c|c|c|c|c|}
\hline & $\begin{array}{c}\text { Reference } \\
(2015)^{*}\end{array}$ & $\mathrm{CO}$ & $\begin{array}{c}\mathrm{CO}_{-} 2 \mathrm{hP} \\
\mathrm{H}\end{array}$ & $\begin{array}{c}\mathrm{CO}_{4} 4 \mathrm{hP} \\
\mathrm{H}\end{array}$ & $\begin{array}{c}\text { Reference } \\
(2029)^{*}\end{array}$ & $\begin{array}{c}\mathrm{CO}_{2} 2 \mathrm{hPH}_{-} \\
2029\end{array}$ \\
\hline $\begin{array}{c}\text { Operating costs of DH system } \\
{\left[10^{3} €\right]}\end{array}$ & 5,238 & 5,201 & 5,186 & 5,164 & 5,687 & 5,425 \\
\hline $\begin{array}{c}\text { Savings compared to the } \\
\text { reference case [\%] (Indicator 3) }\end{array}$ & & $0.7 \%$ & $1.0 \%$ & $1.4 \%$ & & $4.6 \%$ \\
\hline
\end{tabular}

*Reference case costs were obtained by constraining the modelled system not to utilize the thermal mass for storage.

The largest saving potential occurred in the 2029 scenario. The energy system of the 2029 is anticipated to have more capital intensive, but efficient technologies, such as large scale heat pumps and centralized solar thermal systems (Table 4). The main reason for much larger operational savings in 2029 was the larger 
capacity of solar thermal technology that was less curtailed when utilizing the thermal mass for storage. Moreover, more refurbished buildings meant that the larger share of buildings behaved as the 1990's building archetype, having larger time constants and lower energy consumption (Indicator 2).

The resulting capacities of the peak biomass boilers for the year 2029 were $52.2 \mathrm{MW}$ in the reference (2029) case and 37.7 MW in the CO_2hPH_2029 scenario. The latter means that taking into account the thermal mass for storage and corresponding reduction in heat demand (indicator 2) when planning future investments, reduced the needed peak capacity. The reduced peak boiler capacity of $14.5 \mathrm{MW}$ represents $14.6 \%$ of the peak DH demand of the city of Sønderborg throughout the year. Although it was not the focus of our study, reduced capacity of the installed plants reduced the total capital costs of the whole energy system by $2 \%$ in 2029 , equal to 770,000 EUR.

Table 8. Difference in generation of district heating plants in the city of Sønderborg compared to the reference case (the first three scenarios compared with the reference case for the year 2015, the last scenario compared with the reference case for the year 2029)

\begin{tabular}{|l|c|c|c|c|}
\hline & $\begin{array}{c}\mathrm{CO} \\
{[\mathrm{MWh}]}\end{array}$ & $\begin{array}{c}\mathrm{CO} 2 \mathrm{hPH} \\
{[\mathrm{MWh}]}\end{array}$ & $\begin{array}{c}\mathrm{CO}_{-} 4 \mathrm{hPH} \\
{[\mathrm{MWh}]}\end{array}$ & $\begin{array}{c}\mathrm{CO}_{2} 2 \mathrm{hPH} \\
{[\mathrm{MWh}]}\end{array}$ \\
\hline Solar heating & 111 & 235 & 247 & 3,762 \\
\hline $\begin{array}{l}\text { Geothermal + biomass driven absorption heat } \\
\text { pump }\end{array}$ & -1 & -44 & -52 & -734 \\
\hline Biomass boilers & -45 & -74 & -68 & $-6,755$ \\
\hline Waste CHP (heat generation) & 0 & 0 & 0 & 30 \\
\hline Gas CHP (heat generation) & 98 & -5 & -36 & 0 \\
\hline Gas boilers & $-1,361$ & $-1,852$ & $-1,460$ & 0 \\
\hline Heat pumps & 0 & 0 & 0 & 169 \\
\hline
\end{tabular}

*The full results of the generation of different energy plants in the reference cases can be seen in Appendix A.

Comparing the CO_2hPH_2029 scenario and the reference scenario for the year 2029, the optimization results showed that large scale solar-thermal was more utilized. Gas boilers and large scale heat pumps had significantly lower heat generation. Although the capacity of solar thermal DH was larger in the year 2029 than in the 2015, the overall capacity of it was still relatively low. However, the results showed that it could be possible that in systems with larger shares of solar thermal $\mathrm{DH}$, the utilization of thermal mass for storage would be even more attractive economically.

\section{Discussion}

One of the main goals of this paper was to focus on the impact of utilizing building thermal mass for storage on district heating supply and its operating expenses. Our analysis showed that operational savings can be much larger in the future, with larger capacities of the intermittent sources installed in the DH system, larger average electricity prices and higher electricity price fluctuations in the energy system. Load shifting in relative terms was mostly utilized in the CO scenario, during the $98 \%$ of the possible time. Although in the $\mathrm{CO} \_2 \mathrm{hPH} \_2029$ load shifting possibility was utilized the most in the absolute numbers (Figure 5), in relative terms its utilization was lower than in the CO scenario, i.e. it utilized $96 \%$ of the total thermal mass 
for storage capacity throughout the year. DSM events were usually triggered in mornings, in the duration of 2-3 hours, and often in the evenings, especially during the winter time with higher overall DH demand. Heating savings related to the activation of thermal mass for storage were assessed using the indicator 2. Only two archetypes did not have heating savings in $\mathrm{CO} \_2 \mathrm{hPH}, \mathrm{CO} \_4 \mathrm{hPH}$ and CO_2hPH_2029 scenarios. All other building archetypes had heating savings, resulting in a lower overall DH demand. One should note that the latter means that certain share of load shifting occurred due to the energy savings itself. In order to check the share of savings that comes from reduced average temperature when activating the thermal mass for storage, simple sensitivity analyses were carried out for $\mathrm{CO} \_2 \mathrm{hPH}$ and $\mathrm{CO} \_2 \mathrm{hPH} 2029$ scenarios. To carry out the sensitivity analyses, the reference heat demand was reduced in order to be equal to the total yearly heat demand in the $\mathrm{CO} \_2 \mathrm{hPH}$ and $\mathrm{CO} \_2 \mathrm{hPH} 2029$ scenarios. The sensitivity analyses showed that the operational economic savings in the $\mathrm{CO} 22 \mathrm{hPH}$ scenario reduced from $1.0 \%$ to $0.17 \%$. In the CO_2hPH_2029 scenario, the operational economic savings reduced from $4.6 \%$ to $3.1 \%$. However, one should note that the actual implementation of the proposed preheating scenarios and heat supply cut-off to the residential building stock requires a central management system, the same one that allows the activation of thermal mass for storage, which would impose a non-negligible capital cost to the system.

All scenarios showed that despite most of the energy plants reduced their generation (Table 8) solar DH increased its useful output in all the scenarios. The latter could be especially observed in the carbon neutral scenario carried out for the year 2029, when 3.8 GWh more solar thermal heat generation was effectively utilized compared to the reference scenario for the year 2029. Moreover, the thermal autonomy was more important factor for triggering DSM events from the system point of view than the energy use intensity of different building archetypes.

There were four main flexibility sources in the modelled energy system: flexible generation of gas driven plants, import/export of electricity over the system boundaries, heat (pit thermal energy) storage and the building thermal mass for storage. In order to check the operation and mutual influence of pit thermal energy storage and the activation of the thermal mass for storage, another sensitivity analysis was carried out for the CO_2hPH_2029 scenario. In the sensitivity analysis, except the biomass boilers capacity which was not constrained, the capacity of pit thermal energy storage was not constrained either. The analysis showed that the optimal capacity of pit thermal energy storage, that minimizes the total socio-economic costs of the energy system, was $158,000 \mathrm{~m}^{3}$, behaving as a seasonal storage. The significantly increased capacity of the thermal storage further reduced the need for additional 10MW of biomass boilers due to the increased utilization of both solar thermal and the thermal mass for storage. The total load shifted by activating the thermal mass for storage in the sensitivity analysis was $34.1 \mathrm{GWh}$, compared to the 32.9 GWh in the CO_2hPH_2029 scenario. The latter shows that the two storage flexibility options are mutually complementary. The thermal mass for storage behaved as intra-day storage, shaving daily peaks in demand, while the pit thermal energy storage behaved more as seasonal storage, shifting lots of excess solar thermal generation during the summer time to the winter time.

In the first three scenarios, the majority of savings came from less utilization of gas boilers. In the CO_2hPH_2029 scenario, the majority of energy savings came from less utilization of biomass boilers. The latter also shows that implementation of thermal mass for storage could lead to savings in consumed biomass, allowing larger amounts of sustainable biomass to be utilized for the transition of the heavy- 
weight transport sector. It was shown that the transition of the heavy-weight part of the transport sector to the renewable one will be especially energy demanding [43].

Compared to the other studies that assessed the potential of thermal mass for storage and were presented in the literature review, our study simulated real existing buildings from our case study. The simulations were detailed, taking transient behaviour into account as opposed to steady-state or quasi-steady-state models. The latter has allowed us to capture the peaks in heat demand just before (when preheating was applied) and after the cut-off events, a finding that would be hard to obtain using less detailed models. Moreover, our study focused on the DH supply system in a holistic way; not just on its electrified part or on integration of intermittent electricity sources by utilizing the thermal mass for storage. On the other hand, because of the coupling of detailed simulation model with the holistic energy supply model, we had to use a two-level approach and not the integrated model. Furthermore, the DSM strategies were implemented on cold weather conditions with very low solar gains and mean daily temperature of $-3^{\circ} \mathrm{C}$, which represented a cold and grey winter day, which is quite common in Danish heating season so that our system level results become more robust. Two other cases were also modelled to estimate the flexibility potential on a more favourable case and on a least favourable one with regards to the thermal autonomy potential of buildings. These were i) an equally cold but entirely sunny day, with an average ambient temperature of $-3^{\circ} \mathrm{C}$ and ii) an equally grey day but colder with an average ambient temperature of $-6^{\circ} \mathrm{C}$. The experiment was run for the newest archetype representing SFH built in the 1990's and showed that the effect of solar gains is significant. In particular, for the clear day the thermal autonomy potential of the newest archetype increased by 7 hours in the cut-off and preheating scenarios due to the highly increased solar gains that coincided with the time of the cut-off. When a colder grey day was investigated, the thermal autonomy potential of the same archetype decreased by 2 hours due to the increased thermal losses. Thus, the flexibility results are subject to significant changes based on the weather conditions. However, it should be noted that the extremely sunny day that was examined represents only $9 \%$ of the days in a typical Danish heating season (October-April), while the share of very cold days, when the average daily temperature falls below $-3^{\circ} \mathrm{C}$, is $10 \%$. In addition, the examined 1990 's archetype in this sensitivity analysis was characterized by a very long time constant and low overall heat loss coefficient, thus benefiting significantly from high solar gains. These results would be different for the older houses. Therefore, it is assumed that our initial choice of day to run the experiments represents the building performance during a Danish heating season quite well. The effect of warmer days on heat savings [kWh] could be further investigated. Overall, it is expected that much warmer days would lead to lower heat savings due to decreased heating demand. . Testing extremely cold ambient temperatures falling below $12^{\circ} \mathrm{C}$ was beyond the scope of this analysis, as this is the dimensioning temperature of heating systems according to the Danish standards, below which the heating systems would not be able to operate sufficiently to achieve acceptable thermal comfort.

Out of other studies, one study showed that between $3 \%$ and $14 \%$ of the load can be shifted by utilizing the thermal mass for storage [18]. Our findings showed that the theoretical potential for load shifting is between $5.6 \%$ and $8.4 \%$ and the economic potential between $5.5 \%$ and $7.7 \%$, according to the different scenarios. Thus, our results were similar with a smaller variation in different scenarios. A grey-box model applied for in [19] showed very low total system cost savings when utilizing the thermal mass for storage. However, if significant electrification of the heating sector would be pursued, thermal mass for storage would lead to more significant savings, up to $15 \%$ [19]. Although our results are not directly comparable, 
the total system costs in our case were also only marginally lower compared to the reference case. Finally, the linear optimization model developed in [20] showed that the thermal mass for storage was mostly utilized to shift the morning peaks and to a some extent the late afternoon peaks. The same behaviour occurred in our case, especially in the colder periods. They have further claimed that smart controls should be invested in approximately $34 \%$ of the buildings. Our findings showed that the system would economically benefit, in terms of operational costs of the district heating system, by equipping up to $98 \%$ of the modelled buildings with smart controls, which equals to $59 \%$ of the total housing stock in the city of Sønderborg. Only the buildings with very low autonomy time should not spend money on implementing smart controls. It is yet unclear what the price of implementing smart controls in district heating systems on this wide scale would be. However, based on the $\mathrm{CO} 2 \mathrm{hPH}$ scenario and assumed lifetime of smart controls of 15 years, the maximum investment in smart controls of 261 EUR per household would be economically feasible. Larger investments in smart controls would not be recuperated by operational savings in the district heating system.

Regarding the building energy simulations, IDA ICE uses a variable time step solver to capture the dynamics of the system. However, the cut-off duration was rounded up on hourly intervals to reduce the complexity of the optimization problem and thus, the computation time. If a simpler optimization problem was to be solved, the implemented cut-off times would be converted to 30-min intervals or less. Thus, the effect of preheating strategies on the heat flexibility potential of the archetypes would be more evident since rounding would be avoided. In addition, it should be noted that despite the preheating set point of $24^{\circ} \mathrm{C}$, the operative temperature inside the buildings could not exceed $22^{\circ} \mathrm{C}$ even in scenario 3 (CO_4hPH), which is due to the high inertia of the internal walls and mass, as well as the relatively short preheating duration. The lowest operative temperature of $18^{\circ} \mathrm{C}$ was selected to determine the duration of the heating cut-off, so that acceptable thermal comfort was ensured according to ASHRAE and Danish standards and also provide some flexibility to the system. One can argue that this temperature might be too low when occupants would be present or too high if no occupancy is assumed during the cut-off times. Therefore, further investigations are proposed that will study a wider range of lowest temperature threshold and its effect on heat flexibility. Another proposal would be to introduce an additional indicator that will represent the deterioration in the thermal comfort from occupant's side. That would give the human perspective to the effect of DSM approaches. Moreover, some tests were run where internal wall mass was neglected from the building models which resulted in a much lower inertia of the building. Consequently, the thermal autonomy potential was decreased in the majority of archetypes since the total heat capacity decreased. Thus, internal walls proved to be decisive for the inertia of the building, which in combination with the Uvalue of the building envelope determine the heat flexibility indicators. Previous work on Danish lowenergy apartments [44] indicated that the thermal autonomy was mainly determined by the heat capacity of internal walls and heat losses from the external walls. Our work validated this finding for older singlefamily houses, too, which consist of less well-insulated building envelope and larger external envelope areas. If extensive refurbishments were to be applied to the building envelope, the effect of the thermal mass would be more pronounced.

The current case only investigated the residential building stock and specifically single-family houses. Thus, the building sample was very homogeneous. It should be pointed out that the investigated building stock did not include low-energy or nearly-zero energy buildings, which would have even longer thermal autonomy potential due to their very well-insulated building envelope. Furthermore, no apartment blocks 
or multi-family buildings were modelled in the current study, which would have lower thermal losses due to decreased external envelope area, leading to potentially higher heat flexibility. If different building typologies had been included, the thermal autonomy results could have been different, resulting in a different triggering of DSM events on the system scale. Also, if commercial buildings are to be included in the analysis, the internal gains and the occupant schedules should be adjusted accordingly. In that case, high internal gains from employees and equipment could potentially create overheating problems especially in newer office buildings, which is a challenge that has to be addressed during the design phase. Hence, the duration and set-points of the preheating strategy would have to be adjusted accordingly, so that they do not lead to very high and uncomfortable internal temperatures. It should be pointed out that this analysis focused only on the heating demand and the heat flexibility that could be provided to the district energy system due to the cold climate. No mechanical cooling is installed in the majority of residential buildings in Denmark. However, in warmer climates, district cooling is one of the promising solutions for increasing energy efficiency of the system [45]. Thus, if a warmer climate had been studied, the thermal flexibility from a cooling perspective would have been relevant, too, as a demand side management technique.

There are several refinements, which could be assessed in the future. First, the simulation strategy we adopted was to return to the operative temperature as quickly as possible after the DSM event. This was facilitated by the cold ambient temperature and the relatively short overheating periods, which led to fast discharging of the thermal mass.

- However, one could try to assess the performance of buildings if much slower temperature increase would be adopted. However, the latter needs to be balanced taking into account the expected thermal comfort, too.

- Second, a future scenario with much more excess heat, solar thermal, heat pumps, geothermal and other renewable (and possibly intermittent) supply sources in the district heating grid could be analysed. Having more options and capacities of low operational cost technologies in the system could increase the activation of thermal mass for storage in order to avoid the utilization of high operating cost technologies.

- Third, as the literature review showed that nearly zero energy buildings have very long autonomy times, one could try to assess the impact of utilizing the thermal mass for storage in a system with a very large share of nearly zero energy buildings. The latter system could represent newly built neighbourhoods connected to DH systems. According to [44], the thermal autonomy times of newlybuilt low-energy apartments in Denmark could exceed $15 \mathrm{~h}$ with a 4 hour-preheating strategy, similar to our CO_4hPH.

- Fourth, the system optimization model currently does not have the possibility of dynamic modelling of the operation of the DH grid. Hence, one of the future research pathways could be soft-linking of the current system optimization model with some of the dynamic models of the DH grid operation. The latter could make results robust for a wide range of operational cases.

Implementing smart controllers in district heating grid on very large scale is a significant feat. Thus, one potential implementation strategy would be to implement it when building refurbishments take place. That would reduce the installation costs and implement the controllers in the buildings that would have longer thermal autonomy times, after being refurbished. 


\section{Conclusions}

This study investigated the potential of thermal building mass for storage in district heating systems. It was conducted as a two-stage analysis, where building performance simulations were run followed by a system optimization analysis. The building stock of Sønderborg was characterized by six archetypes that represented the $60 \%$ of single-family houses in the area. The results were evaluated on basis of two flexibility indicators: thermal autonomy potential that was defined during a heat supply cut-off while the internal temperature did not fall below $18^{\circ} \mathrm{C}$ and the savings in heating demand compared to the reference case. A third indicator was used to evaluate the economics of the system. Three different strategies were investigated: (i) a heating cut-off for a certain number of hours, and preheating of (ii) two or (iii) four hours followed by a heating cut-off. The heating cut-off resulted in energy savings in all archetypes compared to the reference case, as expected. The effect of preheating control up to four hours was found to affect positively the heat flexibility potential of buildings, but should be evaluated individually for each archetype. The experiment of the cut-off was implemented on a cold and grey day, so that the effect of additional gains, such as solar gains, was not considered, while transmission losses through the building envelope were increased. This choice gave a pessimistic prediction to our results. The peak loads that were created after the heating cut-off were mostly determined by the capacity of the heating system (i.e. hydronic radiators) and the duration of the cut-off, which determined the internal temperature. It was concluded that the highest potential for utilization of building thermal mass is provided by houses built after the 1980s, which have well-insulated building envelope and thus, have lower transmission losses. Furthermore, the thermal autonomy potential is better described by the total heat loss coefficient of the building envelope and less by the time constant during these cold and cloudy weather conditions, since heat losses were found to be more dominating in the specific buildings than the embedded thermal mass.

Operational savings in the DH system occurred in all the cases when thermal mass for storage was utilized. The economic savings in operational costs of the district heating system of the city of Sønderborg were in the range of $0.7 \%-4.6 \%$, not taking the cost of smart controls into account. It would be feasible to invest up to 261 EUR per household in the installation of smart controls. The scenario carried out for the year 2029 showed that the benefits of using the thermal mass for storage are much greater in the future than in the current district heating system, due to the larger capacities of intermittent generation that can be successfully integrated in the district heating supply. Moreover, load shifting that is made possible with activation of thermal mass for storage allows for larger load factors of capital intensive-low operating cost technologies, such as central heat pumps.

One of the sensitivity analyses showed that the large-scale pit thermal energy storage is complimentary to the thermal mass for storage, as the former is mainly used for seasonal shifting of load and the latter one for intra-day shifting of load.

All the scenarios showed that the thermal mass for storage allowed more solar thermal district heating to be effectively utilized. The most significant energy savings originated from the less utilized central gas boilers, as well as biomass boilers in the $\mathrm{CO} \_2 \mathrm{hPH} 2029$ scenario. 


\section{Acknowledgments}

812 This work was undertaken as a part of the CITIES (Centre for IT-Intelligent Energy Systems in cities) project no DSF1305-00027B funded by Danish Strategic Research Council. Cooperation with the 4DH project funded by the Innovation Foundation and the ProjectZero, including their representative Nicolas Bernhardi, on obtaining the data for calculations is greatly appreciated. Nevertheless, we are thankful to Sønderborg Fjernvarme, the operator of the district heating system, for providing us a data about the district heating system.

\section{Nomenclature}

CO2_inten $\mathrm{CO}_{2}$ intensity of a certain technology or energy within the system boundaries, ton/ $\mathrm{MWh}$

$821 \mathrm{CO}_{j}$ Costs of $\mathrm{CO}_{2}$ emissions, $€ /$ ton

822 dies_imp $p_{k}$ Price of import of diesel in a specific hour, $€ / \mathrm{MWh}$

823 el_imp_exp $p_{k}$ Price of import or export of electricity in a specific hour, $€ / M W h$

fix_O\&Mi Fixed operating and maintenance costs of energy plants, $€ / \mathrm{MW}$

fuel $_{j}$ Fuel cost of specific energy type, $€ / \mathrm{MWh}_{\text {fuel }}$

gas_imp_exp $p_{k}$ Price of import or export of gas in a specific hour, $€ / M W h$ generation in each hour during the one year), $\mathrm{MWh}$ type of energy, representing the flow in each hour during the one year), MWh

CO Heat supply cut-off strategy

839 CO_2hPH Heat supply cut-off strategy with a 2 hour preheating 
[1] Noussan M, Jarre M, Poggio A. Real operation data analysis on district heating load patterns. Energy 2017;129:70-8. doi:10.1016/j.energy.2017.04.079.

[2] Lake A, Rezaie B, Beyerlein S. Review of district heating and cooling systems for a sustainable future. Renew Sustain Energy Rev 2017;67:417-25. doi:10.1016/j.rser.2016.09.061.

[3] Lund H, Werner S, Wiltshire R, Svendsen S, Thorsen JE, Hvelplund F, et al. 4th Generation District Heating (4GDH). Integrating smart thermal grids into future sustainable energy systems. Energy 2014;68:1-11. doi:10.1016/j.energy.2014.02.089.

[4] Münster M, Morthorst PE, Larsen H V., Bregnbæk L, Werling J, Lindboe HH, et al. The role of district heating in the future Danish energy system. Energy 2012;48:47-55. doi:10.1016/j.energy.2012.06.011.

[5] Werner S. International review of district heating and cooling. Energy 2017:1-15. doi:10.1016/j.energy.2017.04.045.

[6] Zvingilaite E, Balyk O. Heat savings in buildings in a $100 \%$ renewable heat and power system in Denmark with different shares of district heating. Energy Build 2014;82:173-86. doi:10.1016/j.enbuild.2014.06.046.

[7] Heier J, Bales C, Martin V. Combining thermal energy storage with buildings - A review. Renew Sustain Energy Rev 2015;42:1305-25. doi:10.1016/j.rser.2014.11.031.

[8] Hesaraki A, Holmberg S, Haghighat F. Seasonal thermal energy storage with heat pumps and low temperatures in building projects-A comparative review. Renew Sustain Energy Rev 2015;43:1199213. doi:10.1016/j.rser.2014.12.002.

[9] Yan T, Wang RZ, Li TX, Wang LW, Fred IT. A review of promising candidate reactions for chemical heat storage. Renew Sustain Energy Rev 2015;43:13-31. doi:10.1016/j.rser.2014.11.015.

[10] Pereira da Cunha J, Eames P. Thermal energy storage for low and medium temperature applications using phase change materials - A review. Appl Energy 2016;177:227-38. doi:10.1016/j.apenergy.2016.05.097.

[11] Navarro L, de Gracia A, Colclough S, Browne M, McCormack SJ, Griffiths P, et al. Thermal energy storage in building integrated thermal systems: A review. Part 1. active storage systems. Renew Energy 2016;88:526-47. doi:10.1016/j.renene.2015.11.040.

[12] Le Dréau J, Heiselberg P. Energy flexibility of residential buildings using short term heat storage in the thermal mass. Energy 2016;111:991-1002. doi:10.1016/j.energy.2016.05.076.

[13] Reynders G, Nuytten T, Saelens D. Potential of structural thermal mass for demand-side management in dwellings. Build Environ 2013;64:187-99. doi:10.1016/j.buildenv.2013.03.010.

[14] Wolisz H, Harb H, Matthes P, Streblow R, Müller D. DYNAMIC SIMULATION OF THERMAL CAPACITY AND CHARGING / DISCHARGING PERFORMANCE FOR SENSIBLE HEAT STORAGE IN BUILDING WALL MASS. Inst Energy Effic Build Indoor Cli n.d.:2716-23.

[15] Kensby J, Trüschel A, Dalenbäck J-O. Potential of residential buildings as thermal energy storage in 
district heating systems - Results from a pilot test. Appl Energy 2015;137:773-81. doi:10.1016/j.apenergy.2014.07.026.

[16] Pavlak GS, Henze GP, Cushing VJ. Evaluating synergistic effect of optimally controlling commercial building thermal mass portfolios. Energy 2015;84:161-76. doi:10.1016/j.energy.2015.02.073.

[17] Müller D, Monti A, Stinner S, Schlösser T, Schütz T, Matthes P, et al. Demand side management for city districts. Build Environ 2015;91:283-93. doi:10.1016/j.buildenv.2015.03.026.

[18] Masy G, Georges E, Verhelst C, Lemort V, André P. Smart grid energy flexible buildings through the use of heat pumps and building thermal mass as energy storage in the Belgian context. Sci Technol Built Environ 2015;21:800-11. doi:10.1080/23744731.2015.1035590.

[19] Heinen S, Turner W, Cradden L, McDermott F, O'Malley M. Electrification of residential space heating considering coincidental weather events and building thermal inertia: A system-wide planning analysis. Energy 2017;127:136-54. doi:10.1016/j.energy.2017.03.102.

[20] Hedegaard K, Balyk O. Energy system investment model incorporating heat pumps with thermal storage in buildings and buffer tanks. Energy 2013;63:356-65. doi:10.1016/j.energy.2013.09.061.

[21] Equa. IDA Indoor Climate and Energy. EQUA Simulation AB. 2017.

[22] Kern-hansen C. Technical Report 13-19 2001 - 2010 Danish Design Reference Year - Reference Climate Dataset for Technical Dimensioning in Building, Construction and other Sectors Peter Grunnet Wang Kim Bjarne Wittchen Colophon 2013.

[23] Coskun C, Ertürk M, Oktay Z, Hepbasli A. A new approach to determine the outdoor temperature distributions for building energy calculations. Energy Convers Manag 2014;78:165-72. doi:10.1016/j.enconman.2013.10.052.

[24] Gianniou P, Heller A, Nielsen PS, Negendahl K, Rode C. Aggregation of building energy demands for city-scale models. BS 2015 - 14th Int IBPSA Conf 2015:704-11.

[25] TABULA Project Team. TABULA-Typology Approach for Building Stock Energy Assessment. Main Results of the TABULA project n.d.:43. www.building-topology.eu (accessed July 30, 2017).

[26] Wittchen K, Kragh J. Danish building stock typologies and building stock analyses. Participation in the EPISCOPE project. 2016.

[27] ASHRAE. Measurement of energy and demand savings. ASHARE Guidel 14-2002 2002;8400:1-165.

[28] Sarran L, Foteinaki K, Gianniou P, Rode C. Impact of Building Design Parameters on Thermal Energy Flexibility in a Low-Energy Building. Proc. BS2017 15th Conf. Int. Build. Perform. Assoc. San Fr. USA, 2017.

[29] DS/EN 15251. Indoor environmental input parameters for design and assessment of energy performance of buildings addressing indoor air quality, thermal environment, lighting and acoustics. Dansk standard. 2007.

[30] http://www.gurobi.com/. Gurobi 7.52017.

[31] Dominković DF, Bačeković I, Sveinbjörnsson D, Pedersen AS, Krajačić G. On the way towards smart energy supply in cities: The impact of interconnecting geographically distributed district heating grids on the energy system. Energy 2017:20. doi:10.1016/j.energy.2017.02.162. 
[32] Dominković DF, Bačeković I, Ćosić B, Krajačić G, Pukšec T, Duić N, et al. Zero carbon energy system of South East Europe in 2050. Appl Energy 2016;184:1517-28. doi:10.1016/j.apenergy.2016.03.046.

[33] PlanEnergi. Strategisk energiplan for Sønderborg - Sønderborgs energisystem i 2029. 2014.

[34] SparEnergi.dk. https://sparenergi.dk/ n.d. https://sparenergi.dk/ (accessed November 28, 2017).

[35] Aggerholm S. Cost-optimal levels of minimum energy performance requirements in the Danish Building Regulations. 2013.

[36] Wittchen KB, Mortensen L, Holøs SB, Björk NF, Vares S, Malmqvist T. Building typologies in the Nordic countries : Identification of potential energy saving measures. 2012.

[37] Database. BBR database n.d.

[38] COWI. Sønderborg kommune: Strategisk energiplan, kortlægning og basisfremskrivning. 2015.

[39] Danish Government. Strategy for energy renovation of buildings. The route to energy-efficient buildings in tomorrow's Denmark. 2014:54.

[40] Wittchen KB, Kragh J. Energy savings in the Danish building stock until 2050. 10th Nord. Symp. Build. Phys. 15-19 June 2014 Lund, 2014, p. 1277-84.

[41] Nordpool. Nordpool Elspot prices n.d. http://www.nordpoolspot.com/Market-data1/Elspot/AreaPrices (accessed May 27, 2016).

[42] Energinet.dk. Energinet.dk's analysis assumptions 2014-2035, Update September 2014. 2014.

[43] Dominković DF, Bačeković I, Pedersen AS, Krajačić G. The future of transportation in sustainable energy systems : Opportunities and barriers in a clean energy transition. Renew Sustain Energy Rev 2017:16. doi:10.1016/j.rser.2017.06.117.

[44] Foteinaki K, Heller A, Rode C. Modeling energy flexibility of low energy buildings utilizing thermal mass. Proc. 9th Int. Conf. indoor air Qual. Vent. \&amp; energy Conserv. Build., 2016.

[45] Dominković DF, Bin Abdul Rashid KA, Romagnoli A, Pedersen AS, Leong KC, Krajačić G, et al. Potential of district cooling in hot and humid climates. Appl Energy 2017;208:49-61. doi:10.1016/j.apenergy.2017.09.052.

[46] Frederiksen S, Werner S. District heating and cooling. Studentlitteratur; 2013.

\section{Appendix A}

Generation of different plants in reference cases for the year 2015 and 2029:

\begin{tabular}{|l|l|l|}
\hline & $\begin{array}{l}\text { Reference } \\
(2015) \\
{[M W h]}\end{array}$ & $\begin{array}{l}\text { Reference } \\
(2029) \\
{[M W h}\end{array}$ \\
\hline solar heating & 3,362 & 30,683 \\
\hline geothermal + biomass ab. Heat pump & 77,930 & 60,108 \\
\hline biomass boilers & 27,034 & 95,593 \\
\hline waste CHP heat & 170,346 & 174,637 \\
\hline
\end{tabular}




\begin{tabular}{|l|l|l|}
\hline gas CHP heat & 17,833 & 0 \\
\hline gas boilers & 80,184 & 0 \\
\hline heat pumps & 0 & 65,503 \\
\hline wind turbine & 37,488 & 454,875 \\
\hline PV & 13,150 & 54,101 \\
\hline el grid import & 334,300 & 20,030 \\
\hline el grid export & 329 & 242,455 \\
\hline waste CHP ele & 38,366 & 39,333 \\
\hline gas CHP ele & 20,265 & 0 \\
\hline gas import & 602,207 & 169,274 \\
\hline gas export & 0 & 0 \\
\hline gasoline import & 253,169 & 253,169 \\
\hline diesel import & 253,169 & 253,169 \\
\hline
\end{tabular}

947 Activation of cut-off events on hourly resolution in different scenarios:

948 CO scenario:

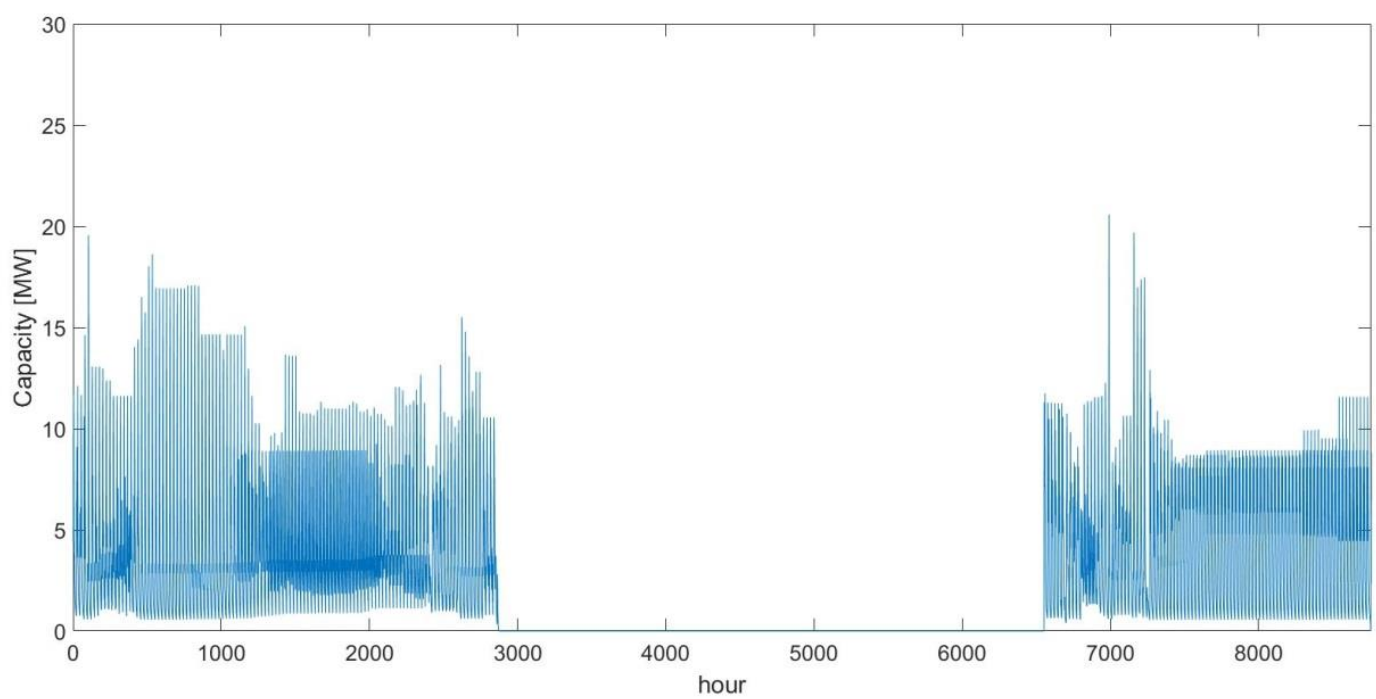

949

950 CO_2hPH scenario: 


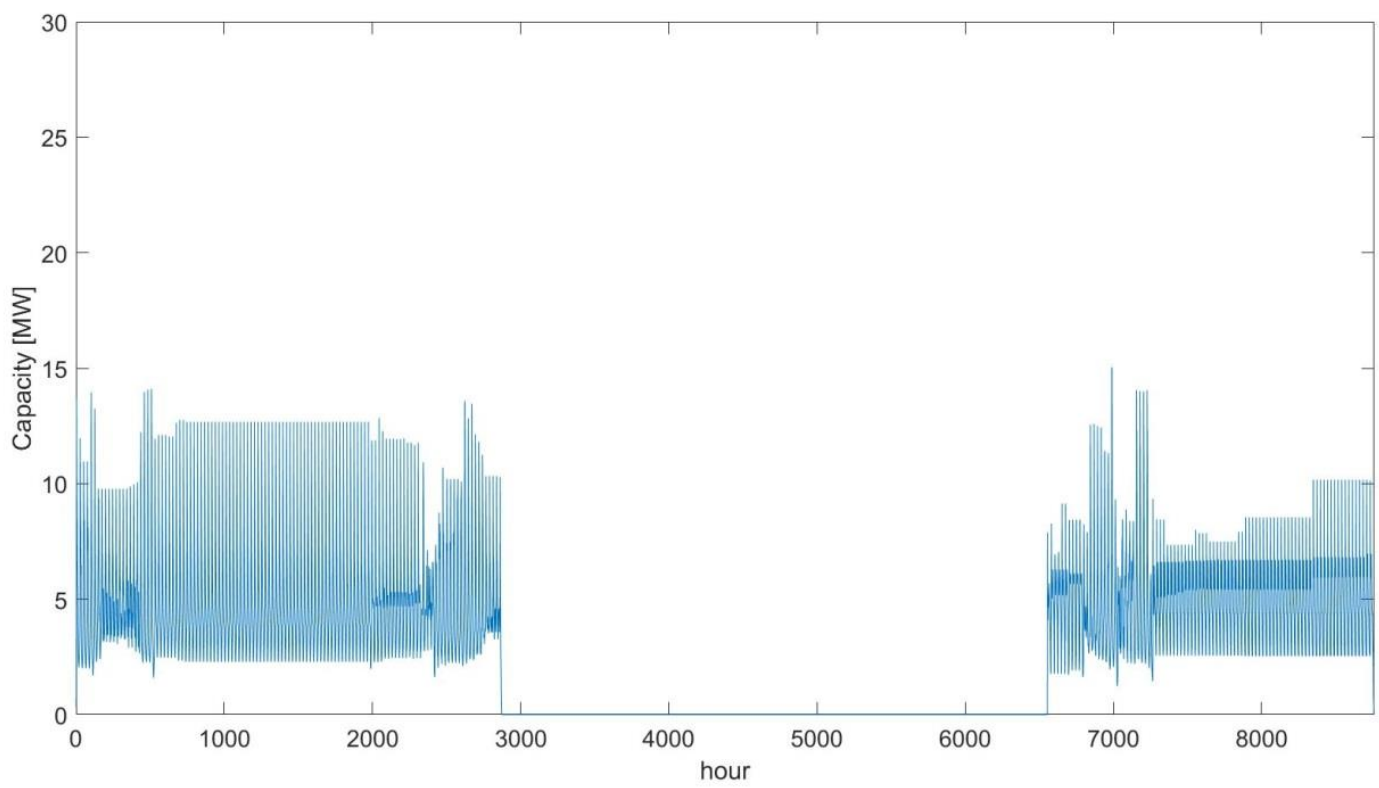

951

952 CO_4hPH scenario:

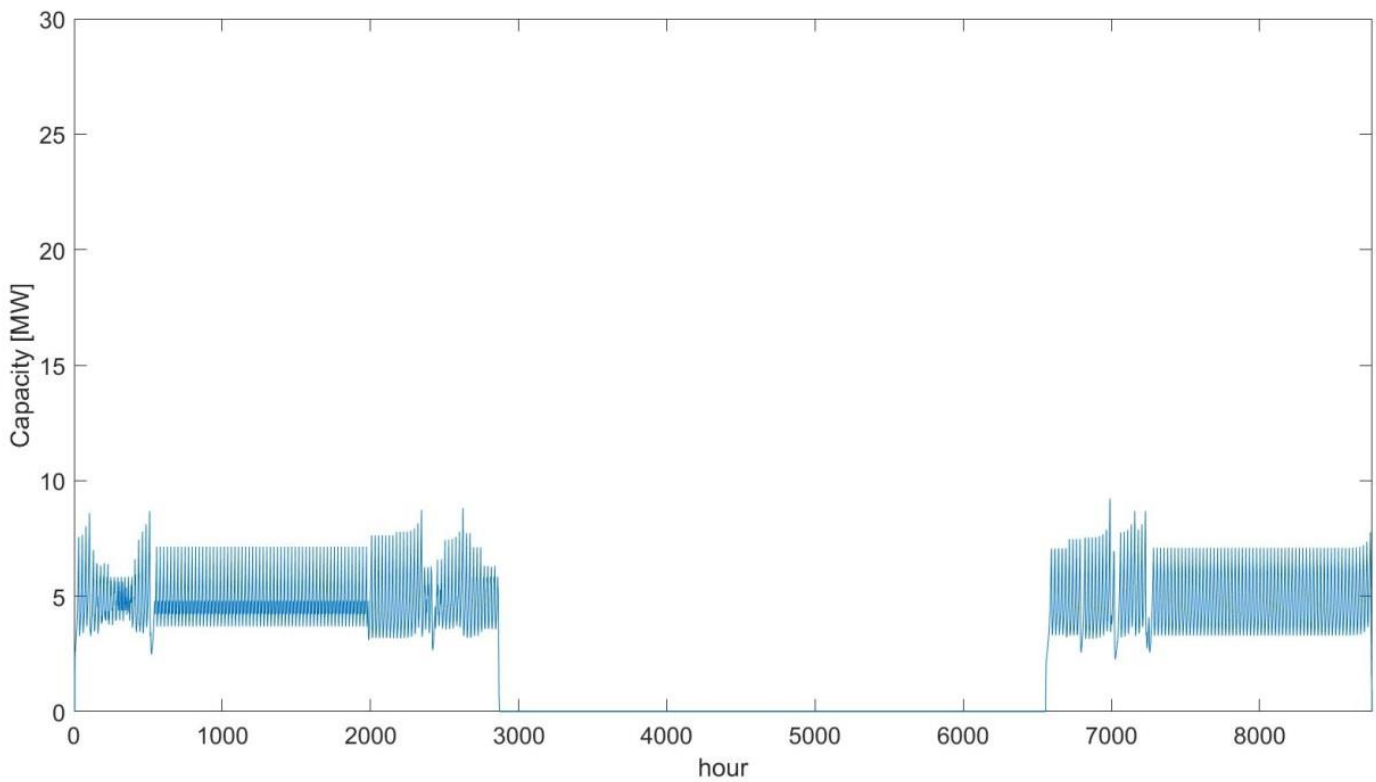

953

954 CO_2hPH_2029 scenario: 


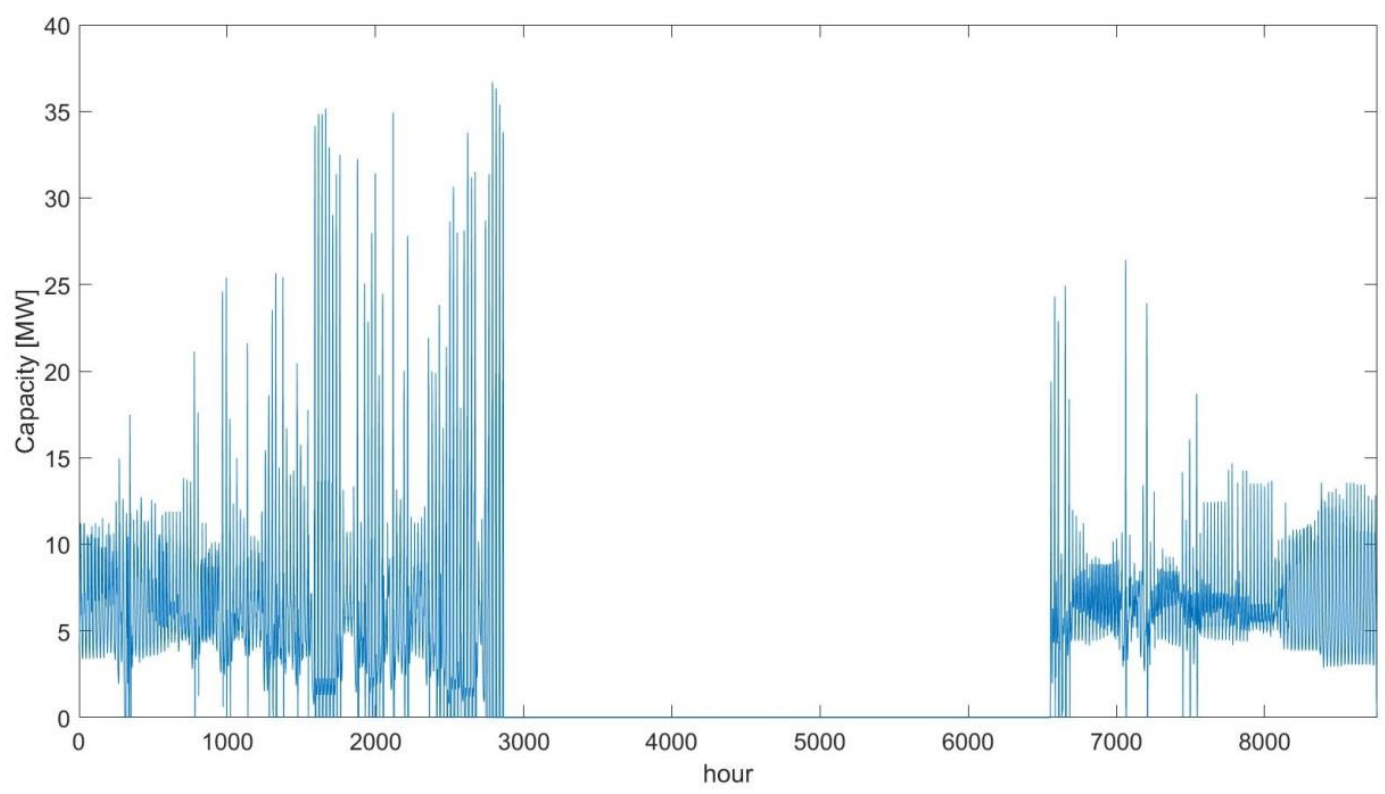

955

956 Appendix B

957

958 Monthly degree-day values for a year according to the given Danish climate file:

\begin{tabular}{|l|l|l|l|l|l|l|l|l|l|l|l|}
\hline Jan & Feb & Mar & Apr & May & Jun & Jul & Aug & Sep & Oct & Nov & Dec \\
\hline 536 & 533 & 463 & 355 & 177 & 95 & 60 & 50 & 126 & 237 & 324 & 469 \\
\hline
\end{tabular}

959

960 Annual outdoor temperature distribution:

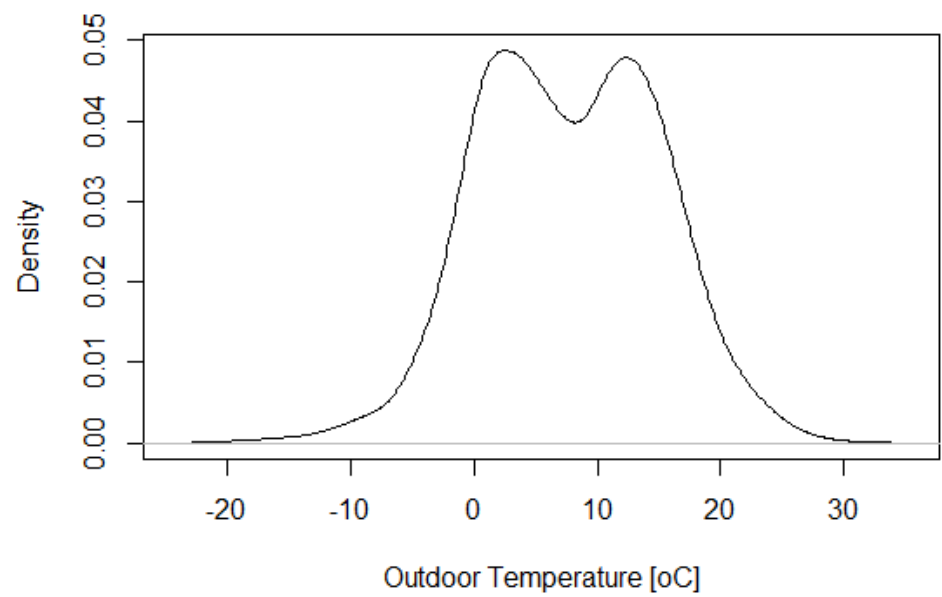

961

962 Global radiation amount for an exemplary week in January: 


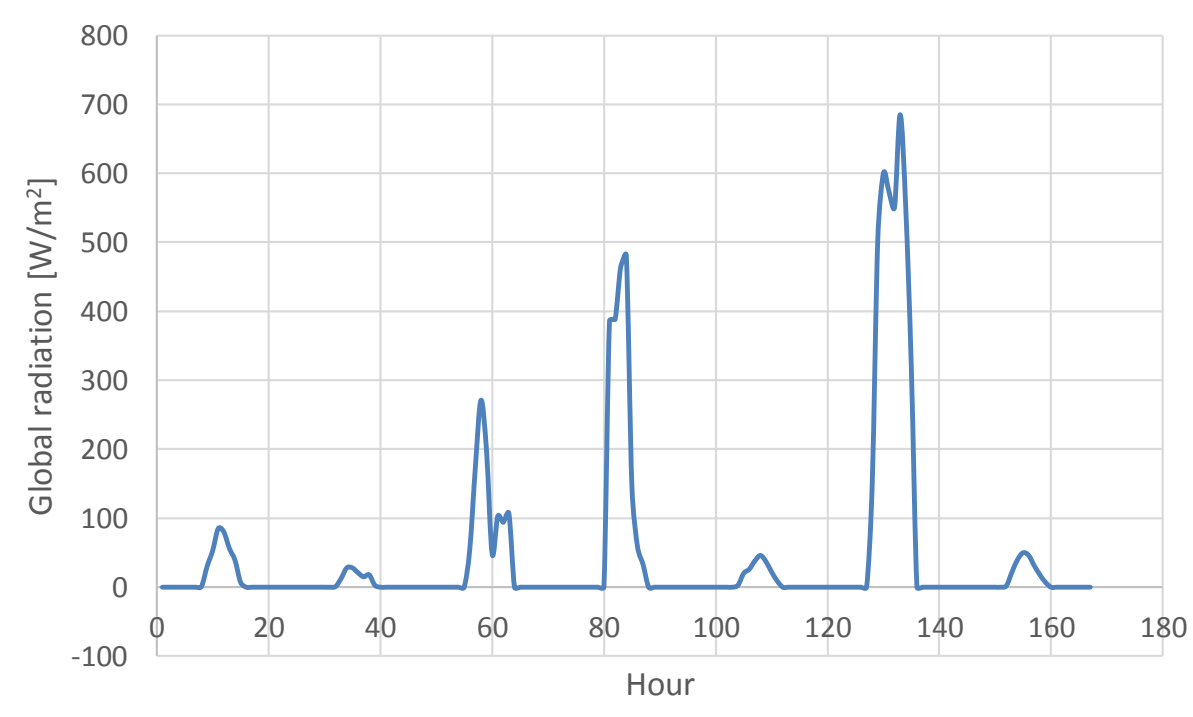

964 Hourly supply and return temperatures, as well as total delivered district heating energy to the end users, obtained from Sønderborg Fjernvarme (the operator of the DH grid):

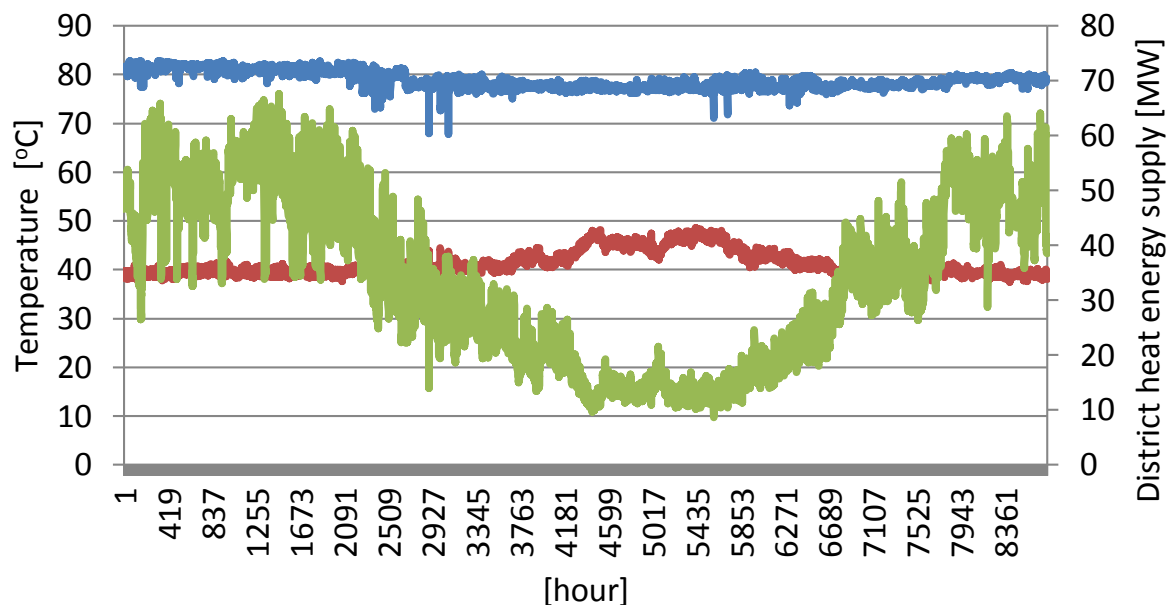

Hourly volume flow (obtained from Sønderborg Fjernvarme) and estimated hourly pumping demand in the $\mathrm{DH}$ grid (total yearly pumping electricity demand is equal to the $1 \%$ of the final $\mathrm{DH}$ energy demand, in line with the pumping energy demand reported in [46]): 


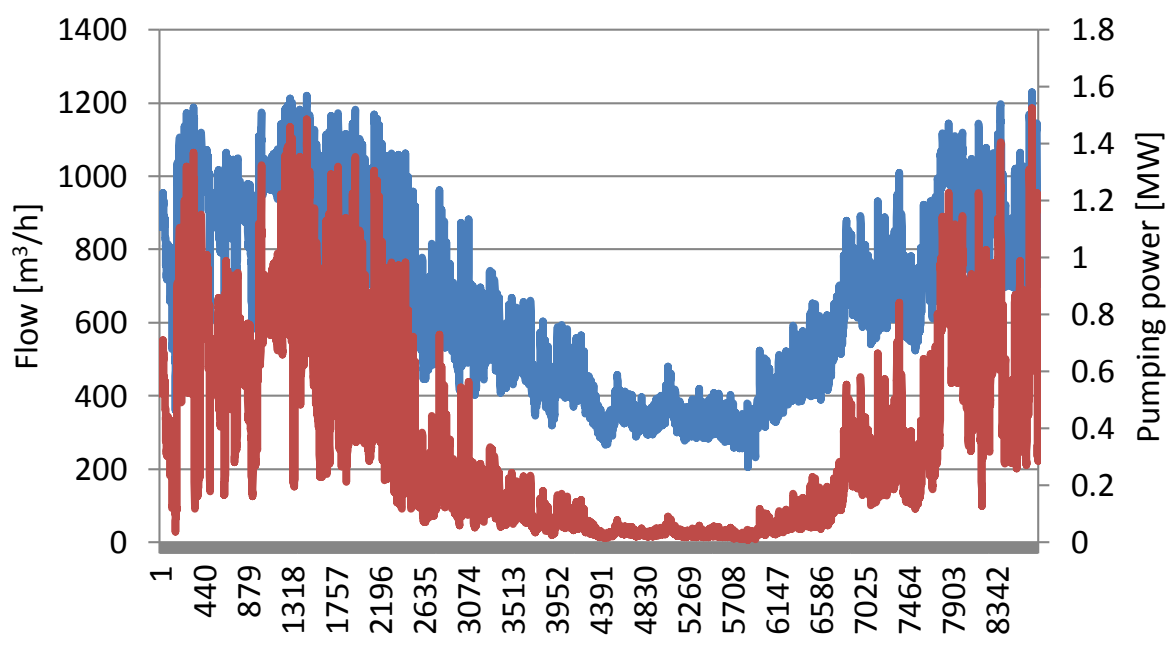

971

972

973 